\title{
Factors Affecting Consumer Acceptance and Use of Child Restraint Systems
}

Kathleen Weber

Nancy Palchik Allen

Highway Safety Research Institute

The University of Michigan

Ann Arbor, Michigan 48109

Contract No. DTNH 22-81-C-17083

Contract Amount $\$ 39,400$

This document is available to the U.S. public through the National Technical Information Service, Springfield, Virginia 22161 
This document is disseminated under the sponsorship of the Department of Transportation in the interest of Information exchange. The United States Government assumes no liability for its contents or use thereof. 
ITechaical Repert Decumentotion Page,

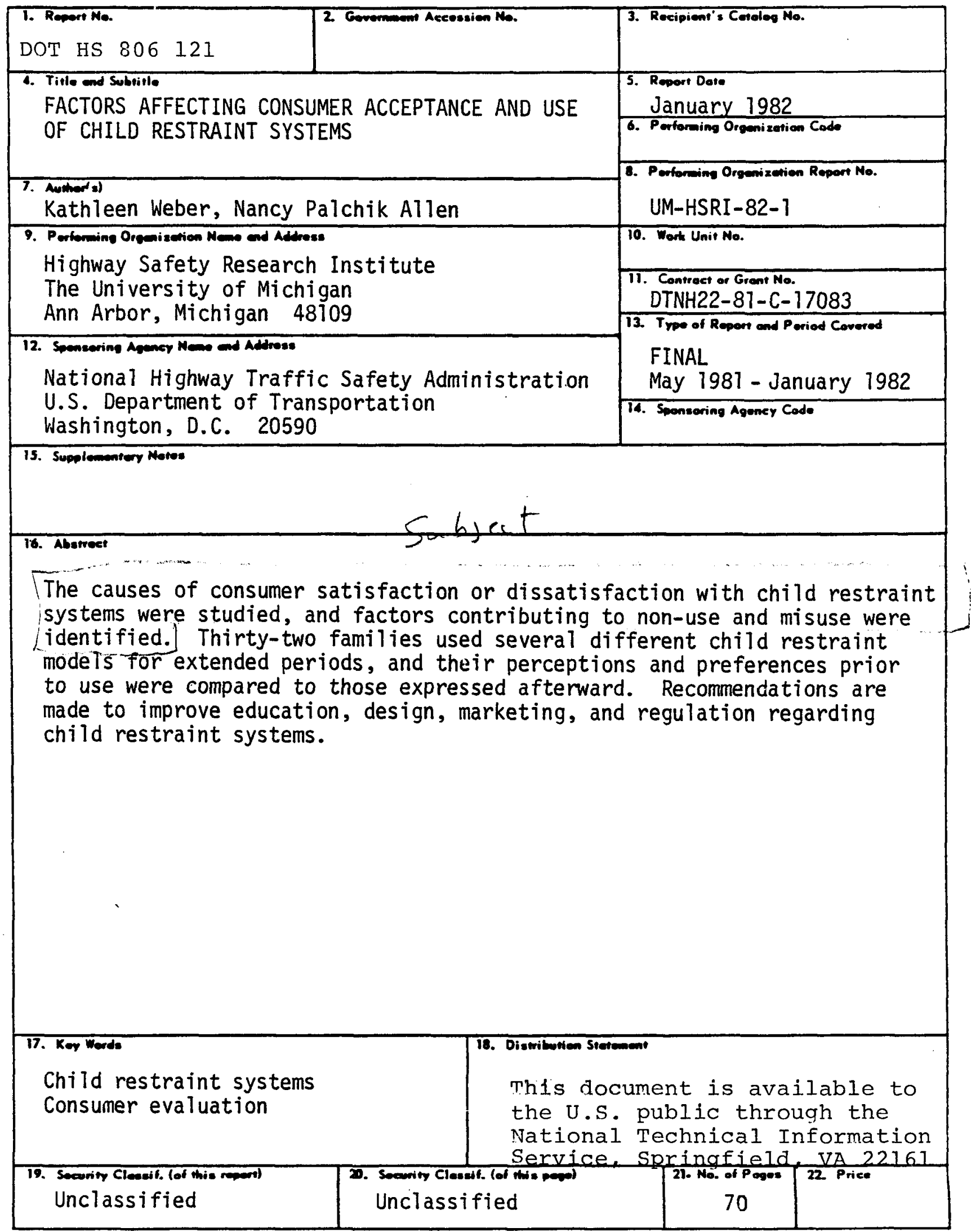


METAIC CONUEASION FACTOAS

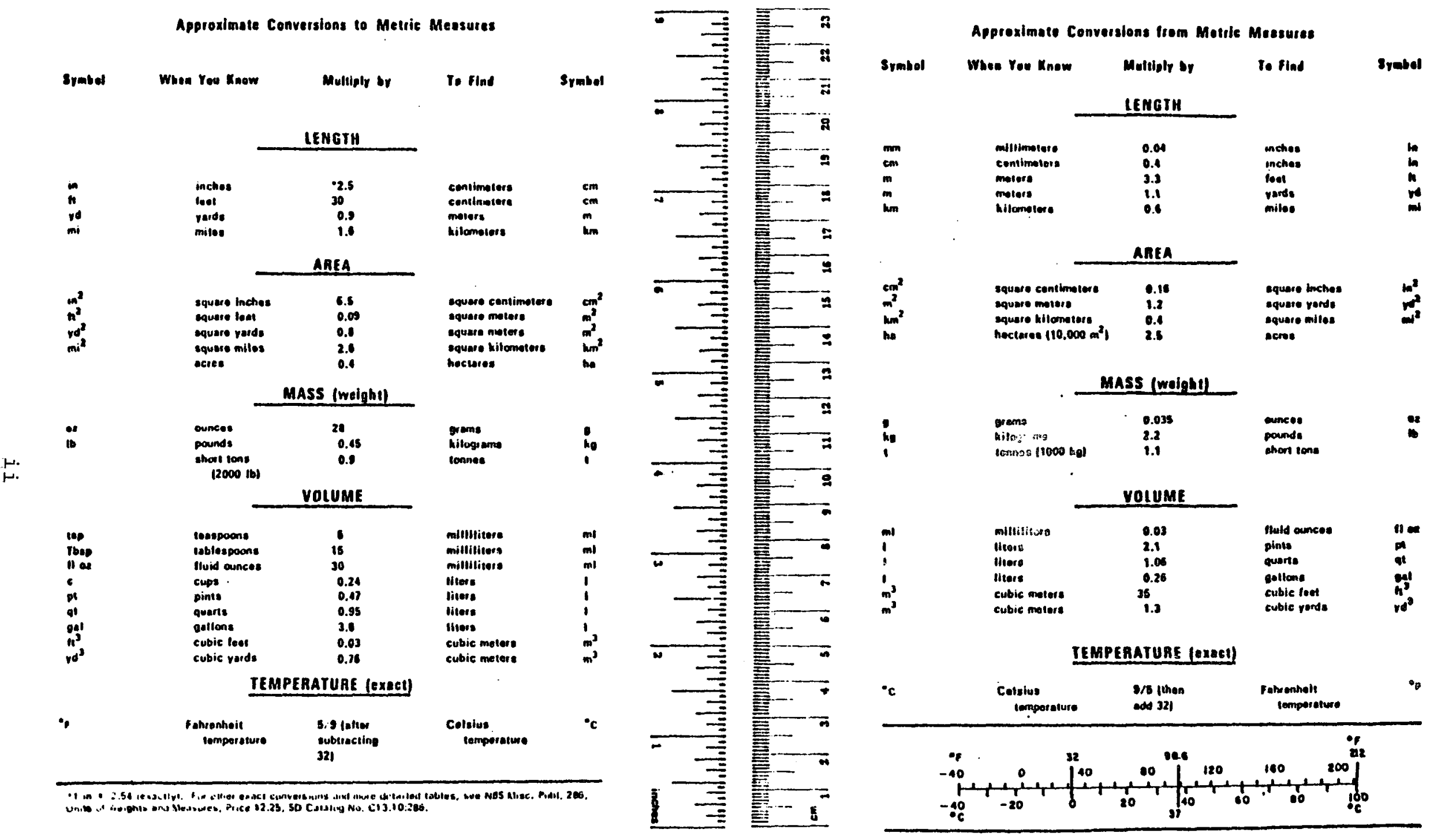




\section{ACKNOWLEDGMENT}

The authors would like to express their appreciation to Joseph B. Benson for his technical assistance, Paula Lux for her artistic work, and Leda Ricci for her production assistance. 
ACKNOWLEDGMENT .........................

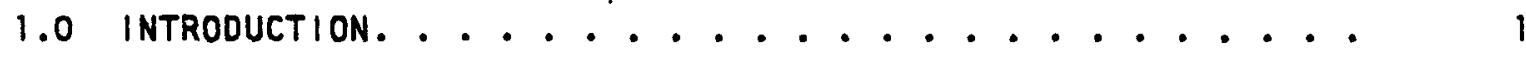

2.0 LITERATURE ReVIEW . . . . . . . . . . . . . . . 3

3.0 METHODOLOGY .......................... . . . 7

3.1 Subjects . . . . . . . . . . . . . . . . 7

3.2 Child Restraint Systems............... 9

3.3 Experimental Design................ 17

4.0 RESULTS . . . . . . . . . . . . . . . . . . . 21

4.1 Initial Choice Phase: Pre-Trial Opinions....... 21

4.2 Initial Use Phase. . . . . . . . . . . . . 24

4.3 Extended Use Phase............... . 26

4.4 Final Choice Phase: Post-Trial Opinions. . . . . . 37

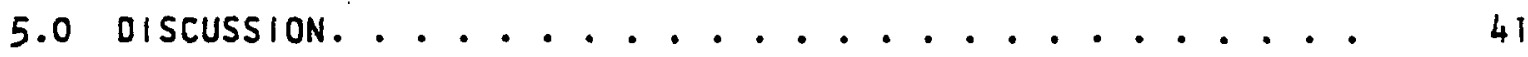

5.1 Changing Criteria and Perceptions.......... 41

5.2 Influences on Child Restraint Design ......... 44

5.3 Consumer Information Gaps. . . . . . . . . . . 47

5.4 Sources of Misuse and Non-Use. . . . . . . . . . . 48

6.0 CONCLUSIONS AND RECOMMENDATIONS.................. 49

7.0 REFERENCES. . . . . . . . . . . . . . . . . . . 51

APPENDIX . . . . . . . . . . . . . . . . . 53 
Page

1. Subjects... . . . . . . . . . . . . 8

2. Child Restraint Design Features. . . . . . . . . 16

3. Use Matrix... . . . . . . . . . . . . 20

4. Initial Choice and Pre-Trial Reactions......... 25

5. Distribution of Vehicle Seat Locations . . . . . . . 26

6. Comparison of Pre-Trial and Post-Trial Opinions. . . . 38

7. Final Choice and Post-Trial Reactions. . . . . . . 40

8. Pre-Trial Versus Post-Trial Selections......... 40 


\subsection{INTRODUCTION}

Few parents properly protect their children in special child restraint (CR) systems when traveling in motor vehicles. The vast majority have not acquired a CR at all, but even those parents who have, do not always use them or use them correctly. Observations in Oklahoma ${ }^{*}$ of over 3,000 vehicles carrying children under age five revealed that, while $13 \%$ of the vehicles contained a CR, children were placed in them in only $9 \%$ of the vehicles. Of the restraints being used, at least $30 \%$ were not being used correctly. In North Carolina, 2 over half of the "car seats" in use were judged to be of unsafe design or misused to the point of being unsafe.

Non-use among families who have acquired a CR can be either occasional or permanent. Among a sample of Oklahoma parents with children under five, $43 \%$ had disposed of a CR they once acquired and had not replaced it. Of these discarded CRs, $87 \%$ had been designed to accommodate toddlers, and $87 \%$ of the parents still had a child who weighed less than 40 pounds. Several studies ${ }^{2,3,4}$ have documented that $C R$ use in this country declines rapidly with the age of the child, with infants being at least five times more likely to be in a CR than 3- and 4-year-olds.

This study is focused on consumer satisfaction or dissatisfaction with child restraint systems for 1 - to 3-year-olds given that a CR has been acquired. Assuming that non-use and misuse result to some extent from dissatisfaction, the study seeks to identify the primary factors that contribute to such occurrences and to suggest ways to eliminate or reduce the effect of these factors. The study is not, therefore, concerned with motivating parents to acquire a $C R$ in the first place, either for an infant or a toddler. It is concerned instead with parents' perceptions and expectations regarding CRs to be used with toddlers once the decision to acquire a CR has been made, and how these perceptions and expectations may change after actual use. Also at issue are design decisions made by CR manufacturers in response both to market experiences and to Federal Motor Vehicle Safety Standard (FMVSS) $2 i 3$, Child Restraint Systems.

\footnotetext{
* Superscript numbers designate References listed in Section 7.0 .
} 


\subsection{LITERATURE REVIEW}

Research on consumer satisfaction with child restraints has generally focused on comfort for the child and convenience for the parent. In a study using safety-motivated families with infants, Webers found that occasional non-use and misuse, both deliberate and inadvertent, directly resulted from inconvenient and uncomfortable CR designs, along with insufficient information on the reasons for correct use. There also was evidence that parents do not have enough information to evaluate whether a particular CR will in fact be acceptable after repeated use. Appearances can be deceiving.

Although infants may in fact be uncomfortable in a given $C R$, especially if it is too upright, discomfort is largely a parental perception and has less of an effect on consumer satisfaction than does convenience. This situation changes when toddlers are involved. Surveys in Tennessee" and lllinois' found that child discomfort and dislike of the CR were primary reasons for non-use, the latter study adding that cost and installation problems were specifically not important factors.

In apparent contrast, Christophersen" reports that children restrained in CRs were considerably better behaved than unrestrained children, and that the latter children suddenly became well-behaved when buckled into a CR for the first time. Cunningham et al.' suggest that child-discomfort excuses, along with inconvenience complaints, may in fact be used because they are "more socially acceptable barriers" to CR use than other reasons parents may actually have.

Implicit in many of these studies is a skepticism that child restraints may in fact be uncomfortable. Among the parents polled in Oklahoma, ${ }^{1}$ who had children under five and who were using or had used a CR at one time, $40 \%$ reported that children do not like to ride in CRs, and $48 \%$ expressed a belief that most parents use CRs to control their children's behavior rather than for reasons of safety. Behavior control is, in fact, a good reason for using a CR, as confirmed by Hall, 10 but only if it works. If, on the other hand, a child is so uncomfortable and resistant to being restrained that $s /$ he tries to and does get out of the $C R$, the parent may as well give up using $i t$. The most frequently mentioned problem among dissatisfied users in the Oklahoma survey was that their children could easily get out of their car seats.

Researchers in New South Wales ${ }^{11}$ have found that children are able to free their arms and upper bodies from virtually any Australian child restraint system. Further, they found this is a widespread problem for parents and often leads to such unsafe behavior as constantly turning to check on the child or giving up trying to restrain the child at all. It should be noted that these restraints have four- or five-point harnesses with no horizontal shoulder strap retainers. Although some children could get out of the straps regardless of how tightly they were adjusted, it was found that loose adjustment contributed significantly to the problem. This was due partly to ignorance, some mothers commenting that they had no idea the straps were to be so tight. But 
another reason was difficult harness adjustment systems that discourage frequent changes and make a snug fit hard to achieve. The study concluded that efforts should continue "to improve the handing qualities of restraints so that parents are less able to use the device incorrectly," and that education programs need to highlight the importance of correct adjustment.

An earlier survey conducted in New South Wales 22 revealed that children opening CR buckles presented just as much a problem as their freeing their arms from the shoulder straps. This has also been a problem with CRs manufactured in the United States's and in Sweden.14 In the latter case, research was undertaken to determine the best design and optional range of force that would make a buckle unlikely to be opened by a child but still easy enough for an adult. Arnbergis recommended a pushbutton mechanism that would release with an average force of 50N, or 11.2 pounds, with a $10 \mathrm{~N}$ margin for manufacturing variability. When this research was incorporated into FMVSS 213 , however, a minimum force of 12 pounds was mandated, which results in an effective average force of 14.3 pounds.2. It has been suggested informally by many that there may be a negative consumer reaction to these stiff buckles.

Although the most extensive research on parental attitudes and behavior with regard to child restraints has been done in Sweden and Australia, not all of the results are relevant to the U.S. market because of different design configurations and installation methods. Swedish CRs face the rear of the car, as do most Australian ones, and the special installation required tends to be rather difficult and permanent. The general problems experienced by parents and children, however, seem to be similar. In a summary of this research, along with results of a new survey and restraint trial program,17,1s the authors found that, while safety was most often stated as the primary reason for restraining a child, controlling the child's behavior was also a frequent motivation for using a CR. Dissatisfaction with particular CRs focused more on child comfort problems, such as heat, sleeping, long trips, strap chafing, and inability to see out the window. Less important were convenience problems, such as harness simplicity, strap adjustment, and ease of cleaning. The problem of not being able to keep the child in the CR was also quite important as it represented a failure of the behavior-control function of the system as well as a failure of its safety function.

An important additional finding " was that different families do have different needs related, for instance, to the number of people in the family, the number of cars, the way cars are used, and the model of the car. In the United States, a simple matter of child-restraint/ vehicle incompatibility can severely limit the CR choice for families with certain model cars. ${ }^{1}$,

Finally, two surveys 1.12 in different countries have come up with the not-too-surprising results that the more families use a CR the more satisfied they tend to be with it; or, conversely, the more satisfied they are the more they use it. There is also a general conviction in the literature that a CR which is easy to use correctly is more likely 
to be correctly used. The key to getting parents and children to use child restraints, and to use them as they were intended, is to insure that each family is well matched with its child restraint and well satisfied with its comfort, convenience, and security. This research program was undertaken to provide information that might facilitate that goal. 


\subsection{METHODOLOGY}

The general research design involved asking parents of toddlers to operate, evaluate, and make a selection among various child restraint systems both before and after the parents had an opportunity to use the CRs for extended periods of time. The pre-trial and post-trial perceptions, preferences, and selection criteria were then compared, and the positive or negative aspects of specific design features were identified. The subject group, the child restraint models used in the study, and the various phases of the experimental program are described below.

\subsection{Subjects}

Thirty-two families with children ranging in age from 12 to 36 months were recruited through local private pediatrician practices. An attempt was made to attract both users and non-users of child restraints with an offer of a free CR at the end of the study. We were soon overwhelmed with potential participants from the user population, both satisfied and dissatisfied. To try to reach more non-users, a special announcement in a University newspaper was made that generated a few additional non-users.

As the subject slots began to $f i l l$, some selection was made based on the age of the child to achieve a reasonable distribution on either side of the near-two-year-old age. As expected, parents of children over 2-1/2 were less interested in the study than were parents of the younger children. The parents who were interested, however, proved to be very interested, as all 32 families accepted into the study remained for its duration. Table 1 summarizes the family descriptors discussed be low.

The average age of the child subjects at the beginning of the study was 22 months (range 12 to 38 months), and their average weight was 26 pounds (range 22 to 32 pounds). Thirteen of the children had no siblings, 16 had one sibling, and 3 had two or more.

The mothers averaged 28 years of age (range 23 to 37 years), and the fathers 29 years (range 23 to 41 years). The parents were relatively well educated, as could be expected in a group motivated to use child restraints,, 20 and there was virtualiy no difference in education level between mothers and fathers. Seventeen of the 64 parents had completed or were working on a graduate degree, 24 more had bachelors degrees, 15 had some college education, and 8 had finished high school. Thus $64 \%$ of the participating parents were at least college graduates.

Reported seatbelt use by the parents was again fairly high, but not unexpected, with the mothers being slightly more conscientious than the fathers. Over half the parents (34) claimed they used seatbelts all or most of the time, while fewer than $20 \%$ (12) said they never used them. 


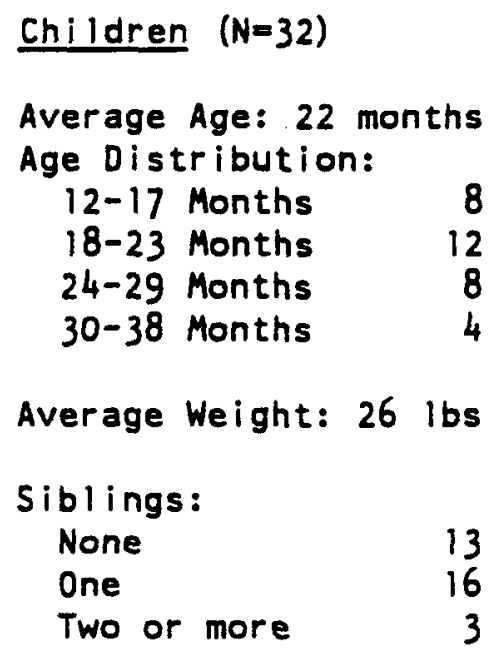

Parents $(N=64)$

$\begin{array}{lr}\begin{array}{l}\text { Average Age: } \\ \text { Mothers }\end{array} & \\ \text { Fathers } & 28 \text { years } \\ & \\ & \\ \text { Education: } & \\ \text { High School } & 8 \\ \text { Some College } & 15 \\ \text { Bachelors Degree } & 24 \\ \text { Graduate Work } & 17 \\ & \\ \text { Seatbelt Use: } & \\ \text { Always } & 23 \\ \text { Most Times } & 11 \\ \text { Sometimes } & 18 \\ \text { Never } & 12\end{array}$

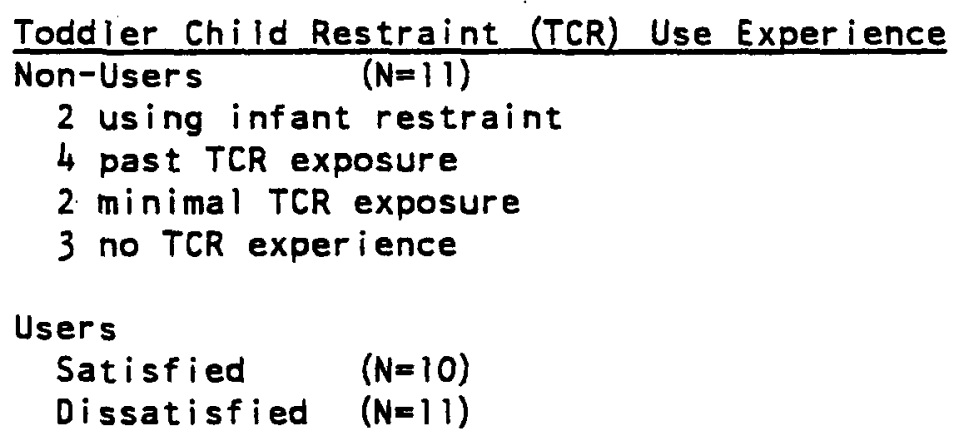

Families came to the study with a variety of child restraint experience that form three general groups of equivalent size: current non-users (11), current satisfied users (10), and current dissatisfied users (11). "User" is defined in terms of using a toddler CR or a convertible CR in the toddler position (TCR). Thus, among the "current non-users," two were still using an infant restraint (although both children were too large), four had used a TCR in the past but had given up, two had very minimal exposure to a TCR, and three had never used one. Only one family had never used any kind of child restraint, either infant or toddler.

The past and present users of TCRs had experience with 30 toddler restraints representing 10 different models. The most frequently used models were the General Motors Child Love Seat (6) and the Strolee Wee Care (6). Although 15 of the 30 CRs required tethers, only three were properly anchored. Parents expressed dissatisfaction with two-thirds 
(20) of the TCRs they were using or had used. The most frequent complaint was that the child could get out, either partially or completely (9), followed by the child not being able to see out (5), harness inconvenience (4), and durability problems (3).

A variety of passenger vehicles were used by the families, including sedans, hatchbacks, station wagons, vans, and pick-up trucks. Four families owned cars in which seatbelt latches in the rear seat were integrated with bulky retractors, a design that is incompatible with many CRs. ${ }^{1}$,

\subsection{Child Restraint Systems}

Multiple samples of eight different child restraint models were used in the study. All were currently on the market (July 1981) and claimed to conform to FMVSS 213, effective January 1, 1981. They were selected to represent the range of differently designed TCRs available to consumers and included various restraining systems, buckle designs, installation methods, shell/frame designs, and upholstery materials. The specific models are listed below along with details about their design features. The abbreviations in parentheses will be used henceforth in the text to refer to these models. Photographs of each are provided as Illustrations 1 through 8 , and possibly confusing or unfamiliar design features are diagrammed and defined in lllustration 9. Table 2 outlines some of the design features for easier comparison and reference.

\section{Astroseat 9100B (AS91)}

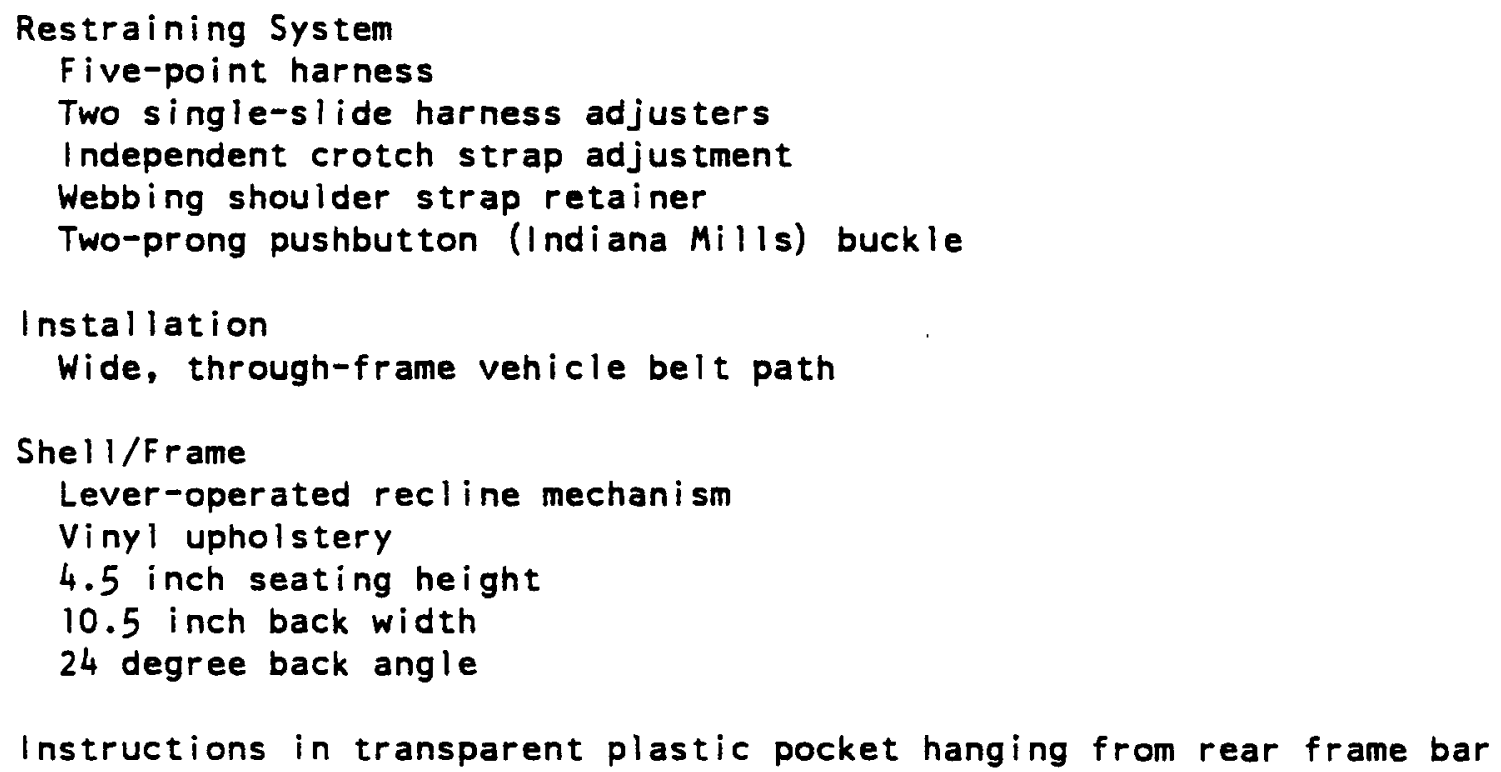




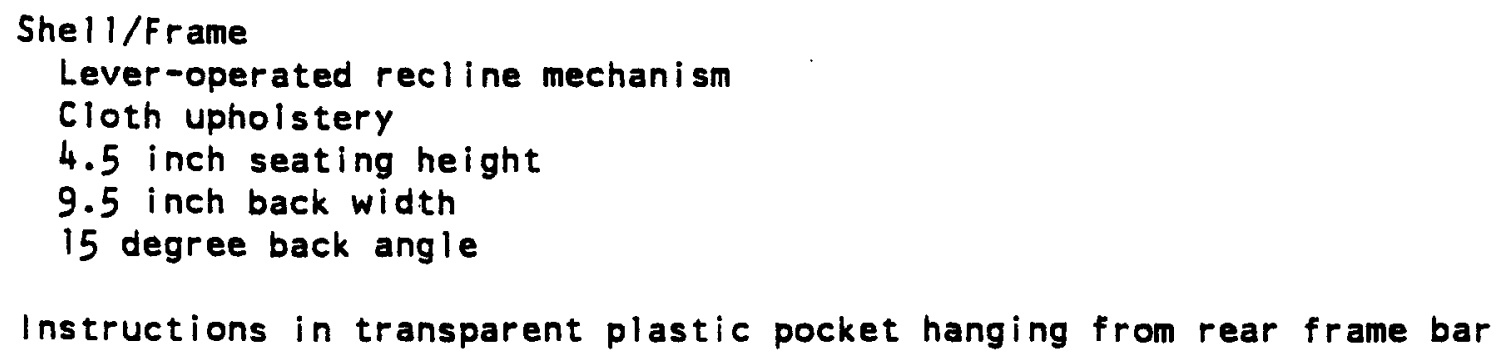

Ford Tot Guard (FTG)

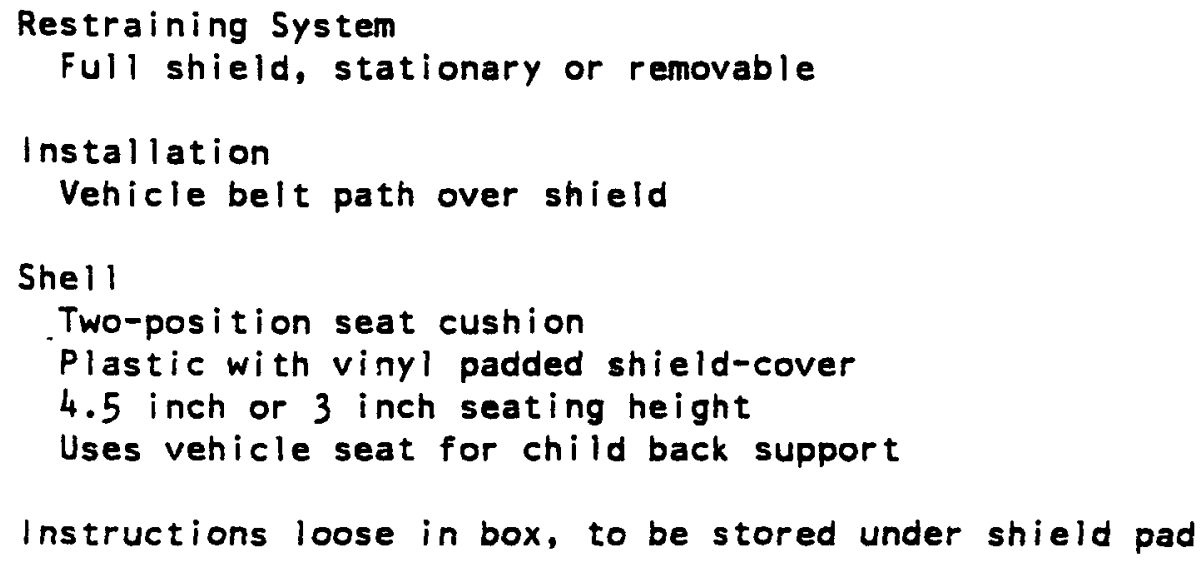

Kantwet One-Step 401 (K401)

Restraining System

Harness with integrated spring-up partial shield

Two double-slide harness adjusters

Crotch strap attached to and adjusts with shoulder straps

One-prong pushbutton buckle

Installation

Wide, through-frame vehicle belt path

Top tether

She ll/Frame

Collapsing-frame recline mechanism

Vinyl upholstery

5.5 inch seating height

10 inch back width

12 degree back angle

Instructions in transparent plastic pocket attached to back of shell 
Kolcraft Hi-Rider (KHR)

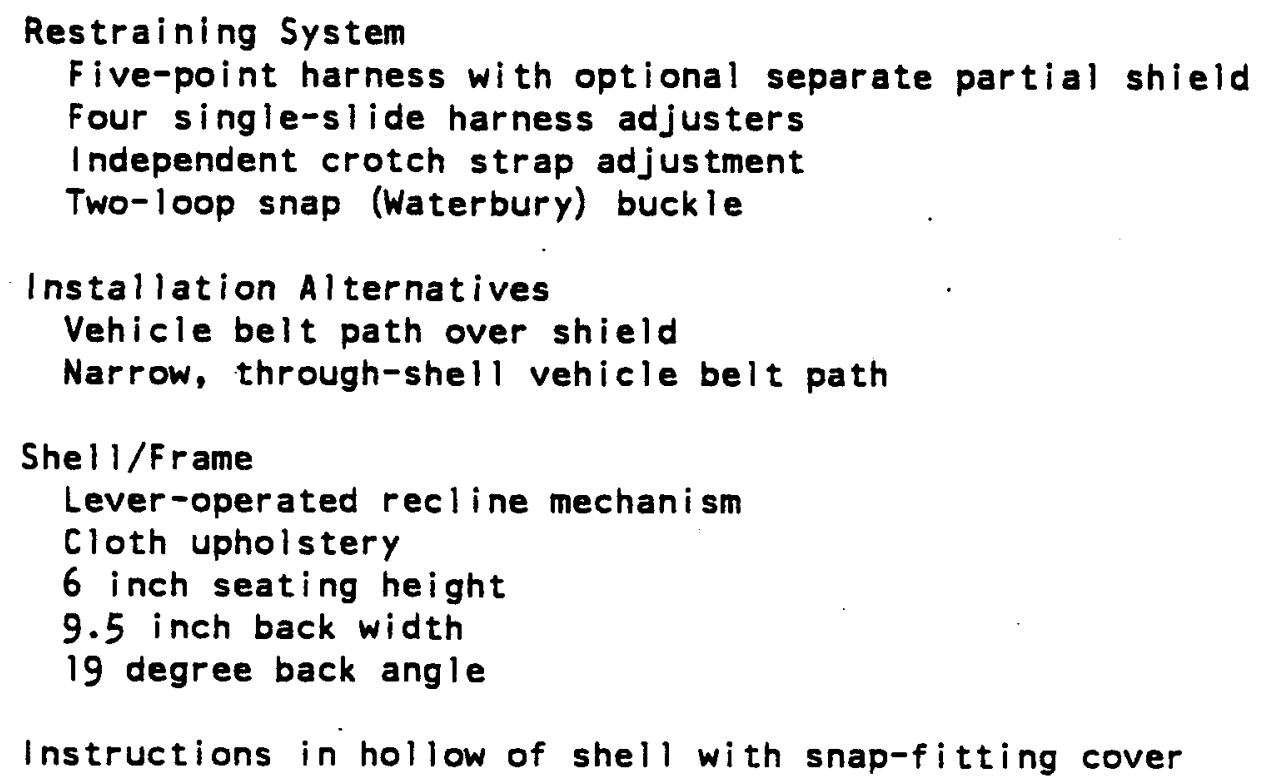

\section{Strolee Wee Care 592 (S599)}

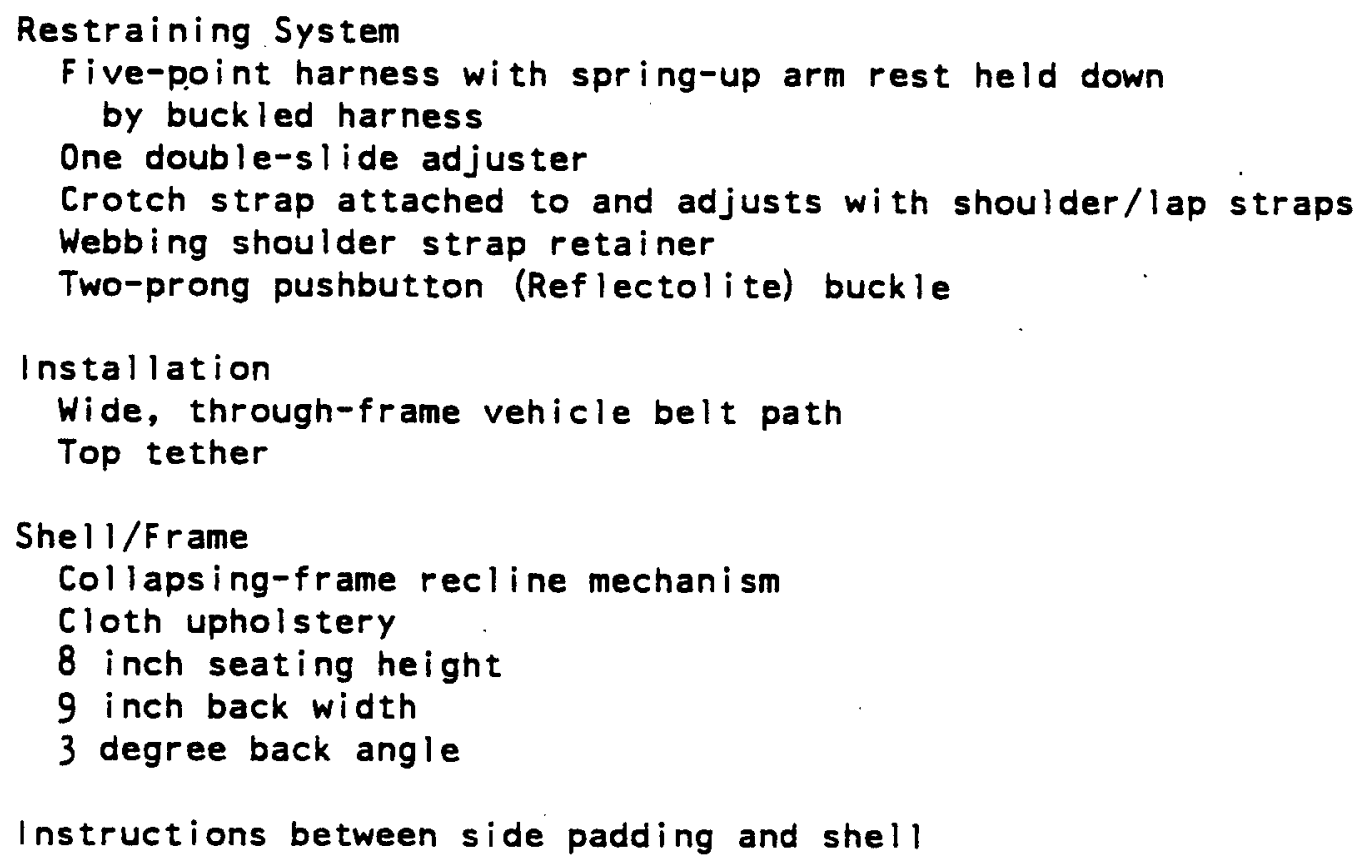




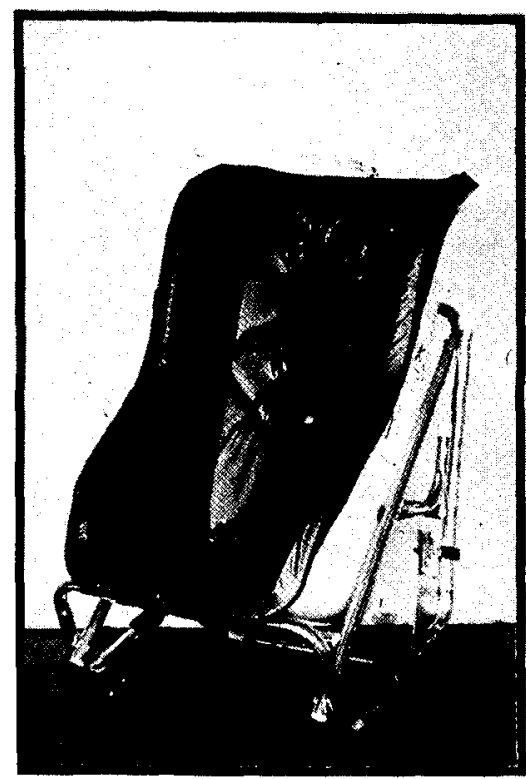

ILLUSTRATION 1

Astroseat 9100B

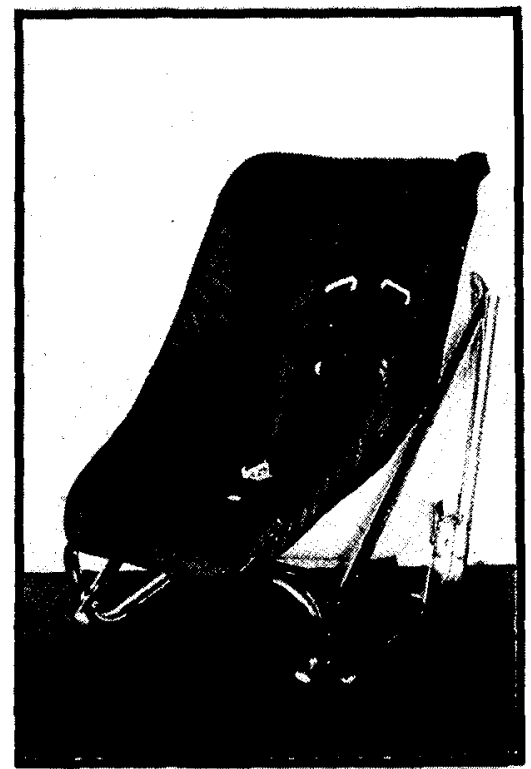

ILLUSTRATION 3

Cosco/Peterson

Safe-T-Seat 78A

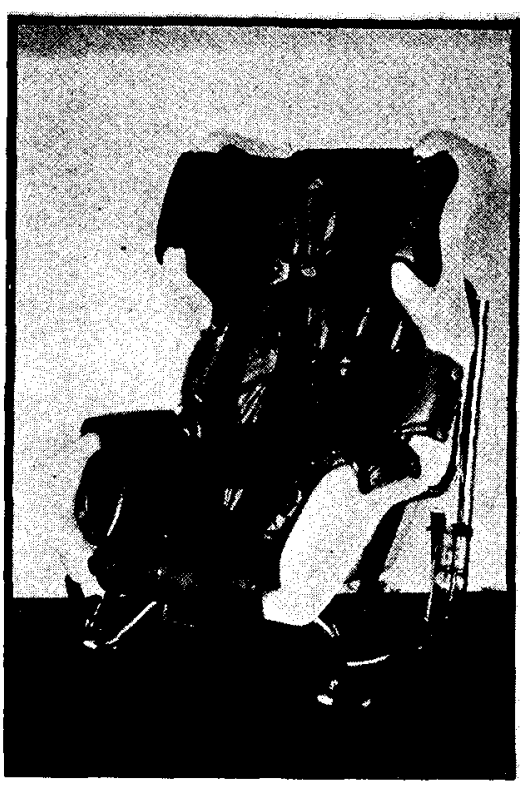

ILLUSTRATION 2

Century 200

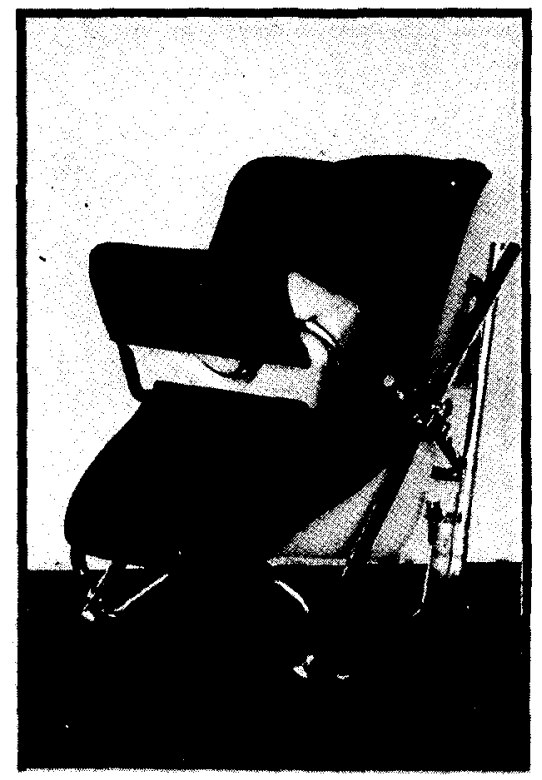

ILLUSTRATION 4 Cosco/Peterson Safe-T-Shield 81A 


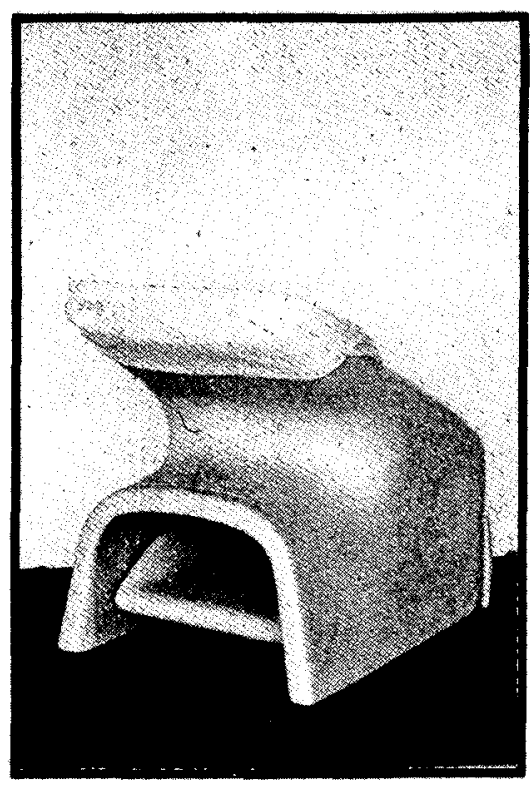

ILLUSTRATION 5

Ford Tot Guard

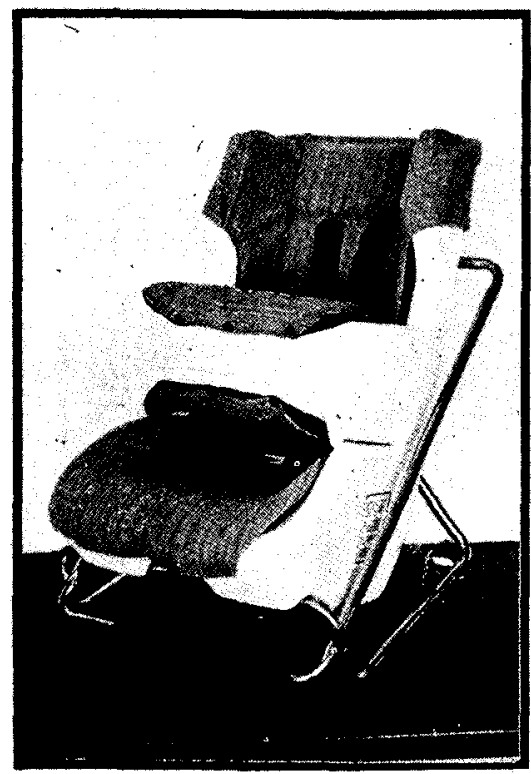

ILLUSTRATION 7 Koleraft Hi-Rider

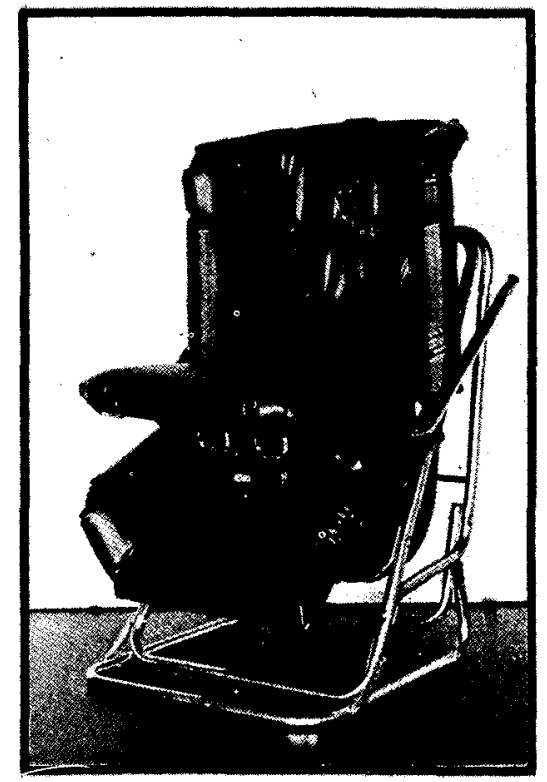

ILLUSTRATION 6

Kantwet One-Step 401

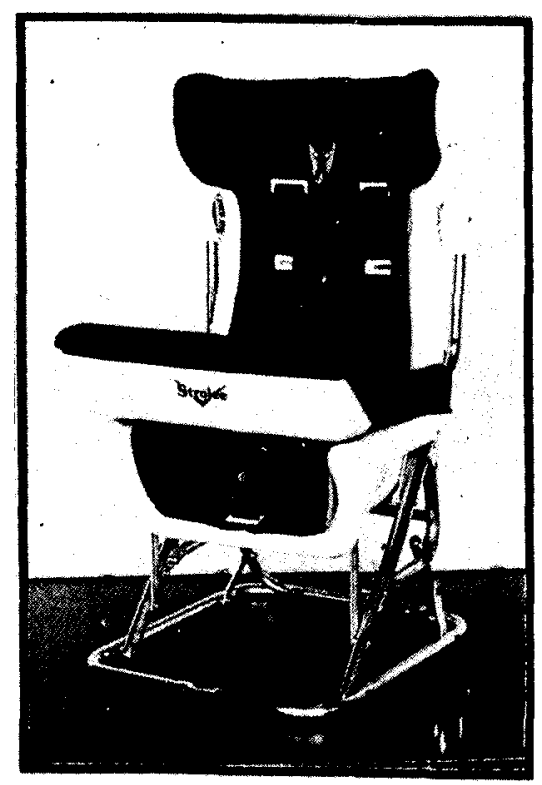

ILLUSTRATION 8

Strolee Wee Care 599 


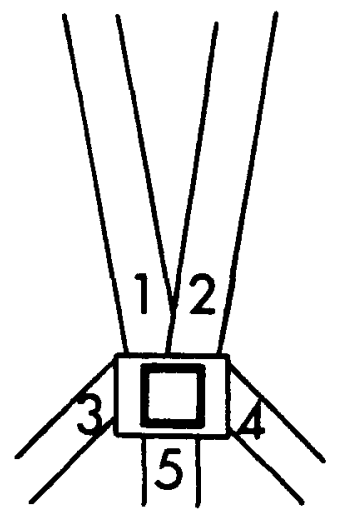

five-point harness

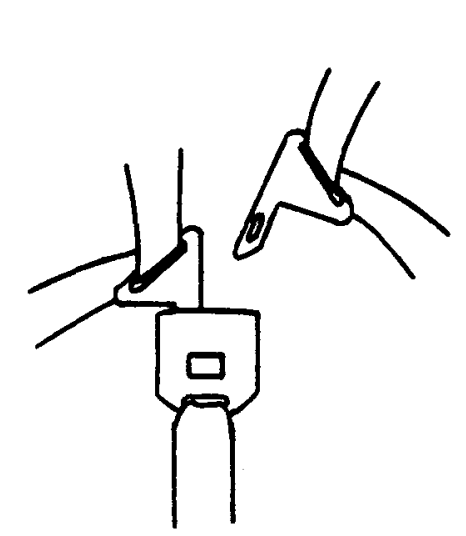

two-prong buckle

two-prong buckle

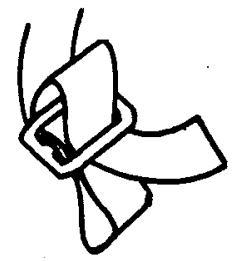

single-slide harness adjuster

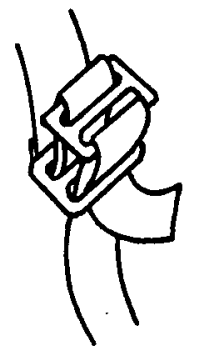

double-sijide harness adjuster

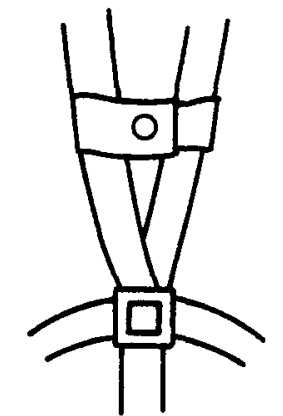

shoulder strap retainer

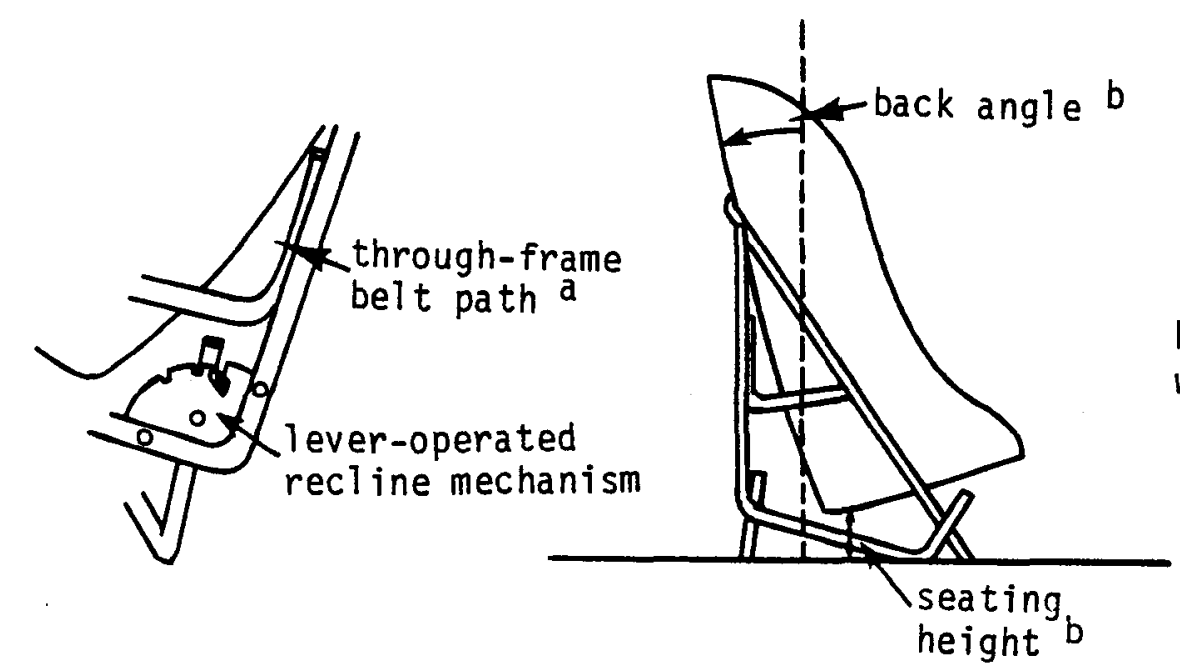

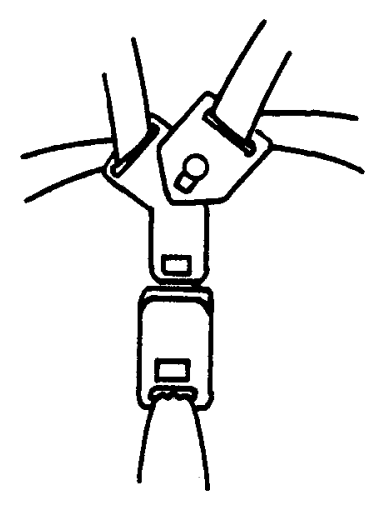

two-part

single-prong buckle

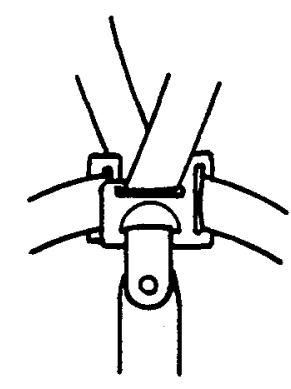

two-loop snap buckle

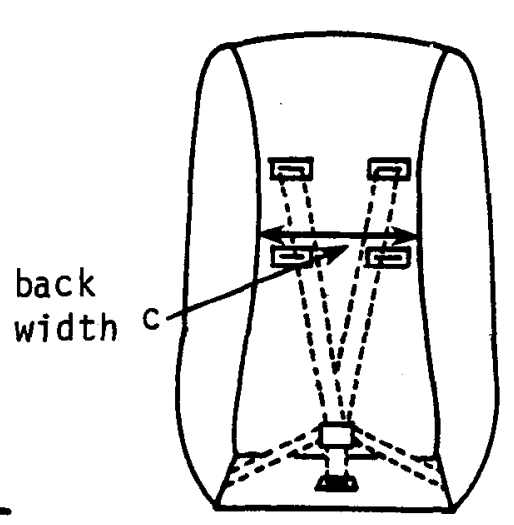

a. Designation of "wide" or "narrow" determined by whether or not space accepts belt latch with integrated bulky retractor.

b. Measured in most upright position.

c. Measured at lower shoulder strap slots. 
TABLE 2. CHILD RESTRAINT DESIGN FEATURES

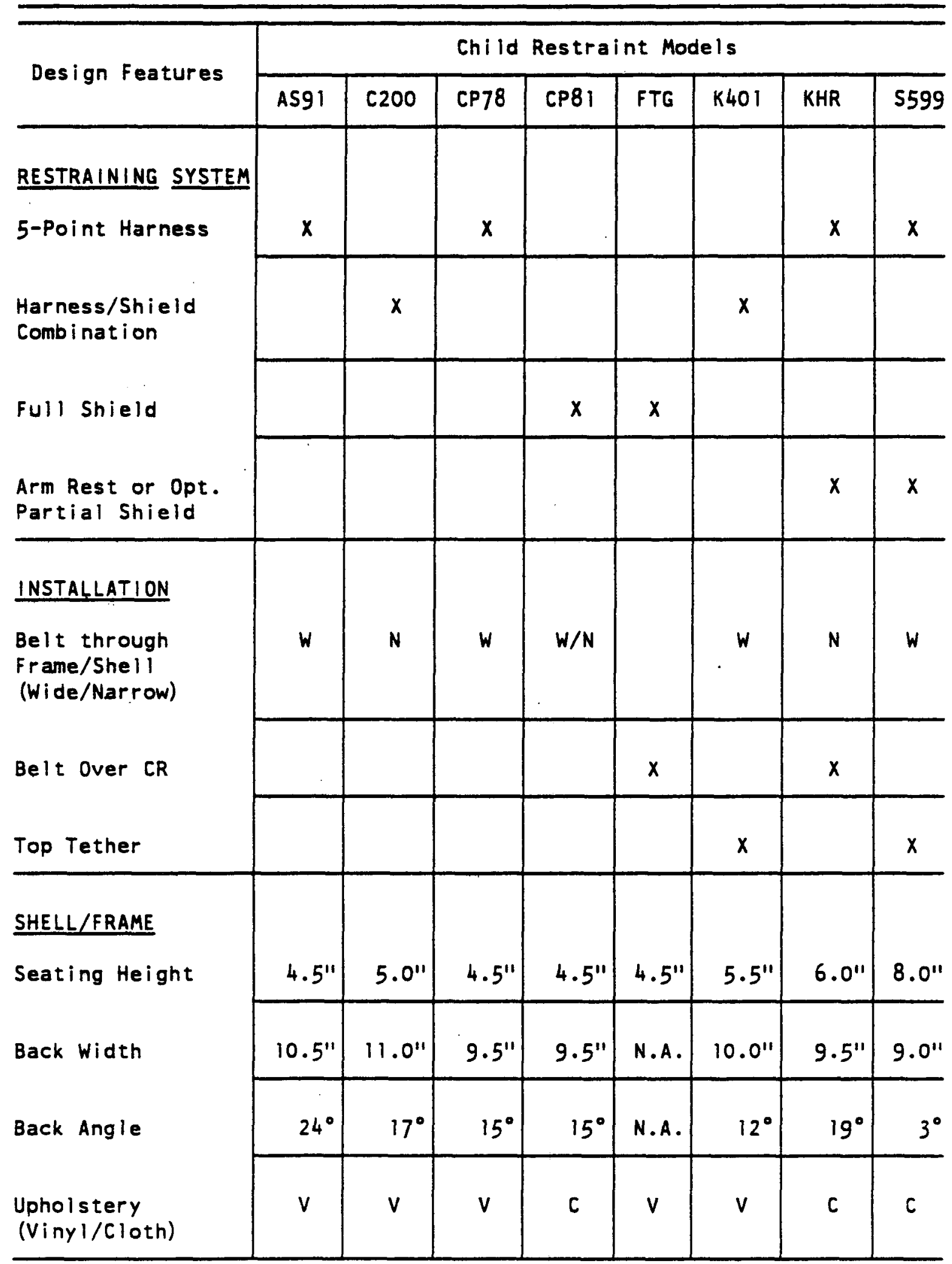




\subsection{Experimental Design}

There were four phases to the experimental program: initial choice, initial use, extended use, and final choice. Each phase involved one or more interview/observation sessions. Parents could participate singly or as a couple and were encouraged to bring their children. Play equipment was available to entertain the children. The experimental program ran from mid-July to mid-November, and thus involved a variety of weather conditions.

Prior to the first interview, background information on each family was obtained over the telephone. Information was obtained about the passenger vehicle(s) each planned to use in the study, and the tether issue was raised. We decided early in the planning phase that the difficulty and inconvenience of tether-anchor installation was wellknown, and that the actual installation could not be left to individual participants. We therefore explained that some CRs in the study needed tethers and that we would install an anchor for the parents if they were willing. Alternatively, they could use a tethered $C R$ in the front seat only, or they could request that no tethered CRs be assigned to them. The decision as to whether to have a tether anchor installed was usually made before the first interview, and appropriate personnel were scheduled to do the job. In all, 11 anchors were eventualiy installed, 3 more families used existing anchors, 9 families used tethered CRs in the front seat, and the remaining 9 did not use any tethered CRs.

Also at this time, one of 32 predetermined series of CRs was assigned to each family. Each series included only four of the eight CRs in the study, but the matrix was carefully worked out so that each model would receive equivalent exposure and comparisons with all other models. Although random series assignments were made when possible, we were sometimes constrained by a subject's tether decision or well-known vehicle/CR incompatibilities. In addition, as the study progressed and other complications arose, a few substitutions and changes in CR order had to be made. Further details are in section 3.3.3.

\subsubsection{Initial Choice Phase}

Parents were shown to a room displaying each CR model in a storelike setting. All placards and the instructions that come with each CR were included. Prices, however, were not given, and parents were asked to assume they were all about the same. They were then asked to "think out loud" while pretending they were shopping for a CR for their child. The parents were told that any questions they might have would not be answered until later. No further instructions were given, although the parents were free to touch, manipulate, read the instructions of, and put their child in any or all of the CRs. The interviewer recorded their actions, reactions, and statements about each $C R$ as well as any comments about child restraints in general. The parents were then asked to select the one they would "buy" and to specify the reasons. They were cautioned that the chosen $C R$ would not necessarily be one they would use in later phases of the study. 


\subsubsection{Initial Use Phase}

The first CR in the family's assigned series was then presented in its box as shipped, except that shoulder straps had been rethreaded to the higher toddler slots when applicable (AS91, C200, CP78, S599), and an infant-only harness had been removed (CP81). (The decision to rethread was made because this operation is usually only done once, the task is not central to the overall study, and this process on one of the models is generally known to be quite difficult and time-consuming, even for experienced users.) In a room equipped with both a "living area" as well as a mock-up of a vehicle seat with center lap belt and tether anchor, the parents were asked to "use" the CR for the first time. The child was present in all but three instances, when a doll the size of a two-year-old was used instead.

Parents were told they would not be given any advice or help, unless they reached an absolute impasse. The instructions, of course, were available for use if needed, but no specific mention was made of them. The interviewer then recorded the actions and comments of the participants and kept track of the time used. After the parents had finished, the interviewer corrected any mistakes made, gave the parents some general guidelines for safe, correct use of CRs, and answered any questions they had. This discussion usually included the importance of snug-fitting harnesses, the function of full shields, partial shields, and arm rests, tricks for dealing with stiff buckles, and tips on how to get vehicle belts and tethers tight. Further information was, of course, provided as the study progressed and questions arose.

\subsubsection{Extended Use Phase}

While they were still at the first interview session, the parents were told they would be using the CR they had just tried for the next three weeks. They were asked to read the instructions at home and to evaluate their completeness, clarity, and general helpfulness. They were encouraged to write their ideas down on a short evaluation form provided (see Appendix). The parents were also given a trip-log form to use primarily as a memory aid for recording their observations, experiences, and problems. An appointment was then made for the next interview.

The interviewer accompanied the family to its car, in which a tether anchor had been installed when appropriate. The interviewer observed and/or assisted the family with the installation and buckling of the CR. Vehicle-related problems were noted, and occasionally a different $C R$ had to be allocated.

After approximately three weeks, the subjects returned for their second visit. They had been told to leave the used CR in their car, partly to ease their load, but also so that its installation could be observed. The parents were then asked to relate what they and/or their child liked and did not like about the CR, any instances when they did not use it or did not use it according to instructions, and whether they would be happy with this CR if they owned it. The interview format was not rigid, but a question/answer form was used as a guide to insure 
completeness and consistency between the two interviewers. This posttrial interview form is included in the Appendix.

After the evaluation of the first CR, the second $C R$ in the family's series was presented and demonstrated. Parents were encouraged to install it themselves on the vehicle seat mock-up and to adjust the harness, if appropriate, to fit their child. The same procedures that were used with the first CR were then followed for the second, third, and fourth restraints.

The validity of self-reported use and misuse has of ten been questioned. A similar previous study," however, found that parents were quite willing to volunteer such information, perhaps because they knew that the CRs and not they themselves were being evaluated. In addition, the fairly lengthy time spent with each family on a repeated basis allowed the interviewers to develop a good rapport with the subjects that encouraged openness and honesty.

By the end of this extended-use phase, records of $126 \mathrm{family/CR}$ use experiences for three-week periods had been obtained, and nine additional shorter-term uses were also documented. These latter were the results either of gross mismatches between family or vehicle and CR, or a desire on the part of the family to try one more CR before making its final decision. The actual use matrix is given in Table 3 . CRs in parentheses indicate short-term use.

\subsubsection{Final Choice Phase}

At the fifth and final interview, after each family had used at least four different CRs, the participants were allowed to select a restraint to take home with them permanently. Parents were again placed in the store-like setting and asked to think out-loud as they evaluated each model. Remember that, in most cases, the parents had actually used only half of the CRs. This time, however, the interviewer did answer questions, especially about CRs a parent had not had a chance to use. Finally, the parents selected the CR they would "buy" and gave the specific reasons for their decision. 
TABLE 3. USE MATRIX

\begin{tabular}{|c|c|c|c|c|c|}
\hline \multirow{2}{*}{ Subject } & \multicolumn{5}{|c|}{ Child Restraint Models } \\
\hline & CR \#1 & $C R \# 2$ & $C R \# 3$ & CR \#4 & $\begin{array}{c}\text { CR \#5 } \\
\text { (Optional) }\end{array}$ \\
\hline $\begin{array}{l}01 \\
02 \\
03 \\
04 \\
05 \\
06 \\
07 \\
08 \\
09 \\
10 \\
11 \\
12 \\
13 \\
14 \\
15 \\
16 \\
17 \\
18 \\
19 \\
20 \\
21 \\
22 \\
23 \\
24 \\
25 \\
26 \\
27 \\
28 \\
29 \\
30 \\
31 \\
32\end{array}$ & $\begin{array}{l}\text { K401 } \\
\text { CP78 } \\
\text { KHR } \\
\text { AS91 } \\
\text { FTG } \\
\text { C200 } \\
\text { CP81 } \\
\text { FTG } \\
\text { S599 } \\
\text { CP78 } \\
\text { KHR } \\
\text { AS91 } \\
\text { CP81 } \\
\text { C200 } \\
\text { CP78 } \\
\text { CP81 } \\
\text { C200 } \\
\text { AS91 } \\
\text { K401 } \\
\text { S599 } \\
\text { S599 } \\
\text { CP78 } \\
\text { KHR } \\
\text { K401 } \\
\text { FTG } \\
\text { CP81 } \\
\text { S599 } \\
\text { C200 } \\
\text { AS91 } \\
\text { C200 } \\
\text { K401 } \\
\text { KHR }\end{array}$ & 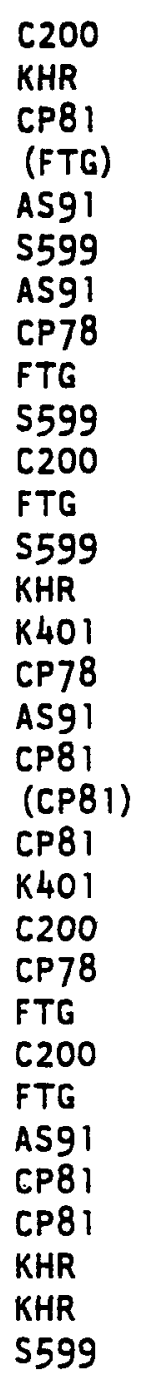 & 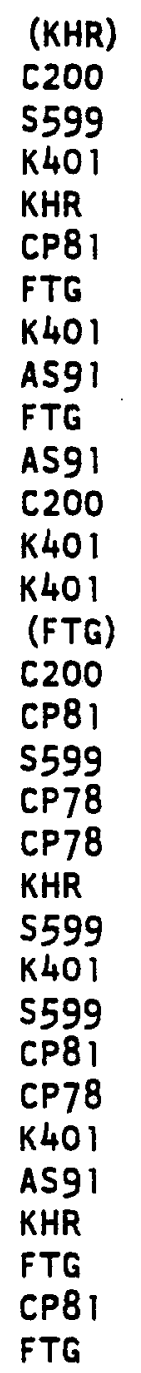 & 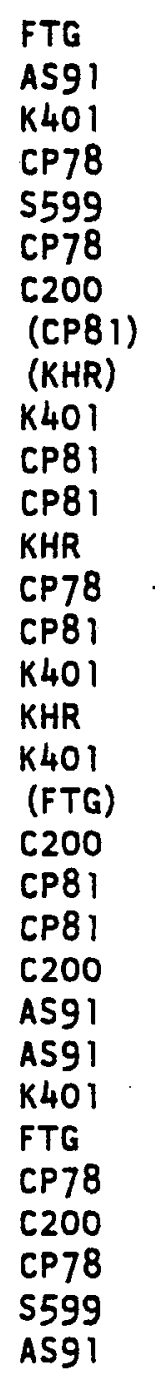 & $\begin{array}{c}C 200 \\
.\end{array}$ \\
\hline
\end{tabular}




\subsection{RESULTS}

Results are presented below in terms of the four phases of the study. Comparisons between results from the pre-trial and post-trial phases are included in Section 4.4--Final Choice.

\subsection{Initial Choice Phase: Pre-Trial Opinions}

Opinions and concerns volunteered by the parents can be grouped into three categories: safety, comfort, and convenience. Although differences among non-users and users, the satisfied and the dissatisfied, were virtually nil, the few exceptions will be noted. There were no identifiable differences related to age of the child.

It is important to remember that the following comments were spontaneous and not made in response to a specific question. Thus, the number of parents who might agree with but did not volunteer a particular comment is not known.

\subsubsection{Safety}

Forty-percent (13) of the parents* expressed the belief that CRs with "something in front of the child" (SIF), i.e., shields or arm rests, were safer than those with belts alone. Three parents said that five-point harnesses were the safest design. Comments made in support of SIFs indicated that parents were skeptical that belts alone would hold, and thus a "double system" was needed. They also wanted something "soft" for their child's head to hit against. Parents saw no distinction between partial shields and non-restraining arm rests.

Another $40 \%$ (13, only 4 parents overlapping with the previous group) indicated that they would choose a CR from which their child could not get out. Almost all (11) were dissatisfied current users (7) or previous users who had given up $(\mathrm{a} / 1$ 4). None of the seven parents with essentially no TCR experience mentioned this selection criterion.

One parent mentioned that a tethered CR was the safest design: This parent was one of the three with a properly installed anchor.

\subsubsection{Comfort}

SIFs received conflicting reviews with regard to child comfort and satisfaction. Again, $40 \%$ (6 parents overlapped with the first group) disliked shields that were big and close, such that they confined the child and blocked his/her view. A third of the parents (11) thought their child would like a "tray table," as the lower SIFs were viewed.

Elevated seating height was important to 13 of the parents, and a roomy sitting space or shell was mentioned by six. Only two mentioned

*For quantification purposes, "parents" refers to the 32 parentpairs who responded either singly or as a couple in this study. An opinion held by both parents was thus counted only once. 
the need for a side head-rest, possibly because it was assumed that all CRs had them. Over half (18) said they would like cloth upholstery, and only two parents added the proviso that it would have to be removable and washable.

\subsubsection{Convenience}

Nearly two-thirds of the parents (20) mentioned a desire for an easy-to-do restraining system. The need for a "quick" system with as few things to do as possible were comments most often added, but two parents wanted an "obvious" system that could easily be done or undone by others. Only two parents said they were looking for ease of installation for switching between cars.

Nine parents said they wanted vinyl upholstery, and 7 were concerned about durability of the covering material. Only two of these overlapped. Six parents said they did not want a top tether, and, despite (or possibly because of) our pre-interview discussion with each parent about tethers, the remaining parents either did not notice them or did not consider them a factor in their decision.

\subsubsection{Pre-Trial Selections}

The most popular models, which were perceived as combining the most popular features, were K40I ( 8 selected), CP81 (7 selected), and 5599 (6 selected). All three have an SIF that was viewed by these parents as not too large or confining, the systems were considered relatively easy to do, and they looked like car seats "should look." Interestingly, two of the three CRs have top tethers, but only three of the 14 parents selecting them indicated they noticed the tethers.

$\mathrm{K} 401$ generally received the most favorable response, with $60 \%$ (19) of the parents reacting positively to it. The simplicity of the buckling procedure and the low, flat "tray table" for the child were its primary attributes. The only significant negative feature was that its vinyl cover appeared "cheap" and prone to tearing. A few parents also found the buckle mechanism too stiff, and others said the tether was unacceptable. Thus 5 parents reacted negatively, 5 were uncertain or neutral, and 3 skipped it entirely, making no comment.

CP81 received a generally mixed response. Although half the parents were impressed by its lack of straps and thus ease of use, several expressed concern that their child would be able to get out, that a shield alone would not be safe, that the child would not like the confined feeling, and/or that $s /$ he would not be able to see over the shieid. Seven parents actually tried their child in the CP81 (an unusual occurrence in this phase), which usually resulted in the child crying. Two of these parents still selected it, one commenting, "She'll get used to it." The cloth upholstery was a favorable feature, but not a controlling factor. In the end, 10 parents reacted positively, with ease of use being the primary reason. Nine gave negative evaluations, because of safety, comfort, and child-containment concerns, and 10 were uncertain or neutral. Three parents skipped it entirely. 
5599 generated less ambivalence. Over $40 \%$ (14) reacted positively, primarily because of the extra seating helght and also because the sif was seen as "safe" while not confining. Some mentioned they liked the buckle, and others said the restraining system looked easy to do, although none of the latter actually tried it. Two parents chose the 5599 because of the manufacturer's "name." Ten parents gave negative evaluations, primarily because the restraining system was too complicated, and also because the shell looked too upright, narrow, and shallow for their child's comfort. A few thought their child would be able to get out of the CR. The tether was a negative factor for 4 parents, and was commented upon by only one of the parents selecting the 5599. Five parents were neutral or uncertain about this $C R$, and 3 skipped it entirely.

Less appealing were the plain five-point harness designs, including CP78 (4 selected) and AS91 $(2$ selected). Those who chose these CRs simply wanted a five-point harness because it was safe and familiar to them. Among all the parents, however, there were really no strong feelings one way or the other about this design.

CP78 received 7 positive reactions and 10 negative ones. Six parents were uncertain or neutral, but 9 skipped it entirely. The most frequent reactions were that the vinyl was especially nice but that the buckle was too complicated. There was also some confusion over the shoulder strap retainer, which two parents saw as a permanently fastened fixture. Thus they wondered how they would get their child in and out. Others who figured it out thought the retainer was too difficult to use.

AS91 also received 7 positive reactions but 16 negative ones. Two parents were uncertain or neutral, and 7 skipped it. This CR did not have the appearance-appeal of the CP78, and $i$ ts buckle was too hard to engage and release. Seven parents specifically commented that there was nothing in front of the child to hold him or her in. A few thought the shell looked uncomfortably deep and narrow.

The remaining three CRs were anomalies in some respect and generated many puzzled reactions. These restraints, KHR ( 3 selected), C200 ( 2 selected), and FTG (none selected), are discussed below.

KHR has an SIF along with a five-point harness, but the detachability of this SIF was viewed negatively because it involved extra handling and might get lost. Many parents figured out or assumed that it was therefore not necessary, and eight specifically said they would not use it. The CR thus became a five-point harness system for these parents. The shield was also found to be difficult to snap in place, and its top/bottom orientation was not obvious. If the shield were used, parents thought the system would be too time consuming. The cloth-covered shell was viewed as roomy and comfortable, and the system did look safe to those who chose it. Seven parents reacted positively overall, 13 were negative, 6 were neutral or uncertain, and 6 skipped it.

C200 has a familiar-looking shell, but its restraining system includes neither a typical sIf nor a five-point harness. The abdominal 
pad looked like it would be heavy, hot, and/or floppy to $40 \%$ (13) of the parents, although others (5) viewed it positively as being soft and not too big. A few said the vinyl looked "cheap," and 3 parents thought their child could get out of the restraining system. Several parents commented on the ease of the single-step buckling system and on the comfortable size and shape of the shell. Still, only 8 parents gave positive evaluations, whereas 10 were negative and 11 uncertain or neutral. Three skipped it entirely.

FTG just did not "look right" to 12 of the parents, and some could not guess how it worked before looking at a picture. Some said or knew from experience their child would get out. Other negative comments were that it looked hard, confining, and generally uncomfortable, and that their child would not be able to see over the shield. Only three said it looked very easy to use. Thus this CR received 22 negative reactions, 3 positive, and 6 uncertain or neutral. Oniy one parent skipped it entirely.

\subsubsection{Summary of Initial Choice Results}

Parents were looking for a familiar-shaped, attractive CR that was safe and durable, was quick to "do up," would raise the child up, would keep the child in place, but would not be too restrictive. Safety, and to some extent child-containment, were dependent on something other than belts wrapping around the child, but this something could not be too high or close-fitting. Three restraints of the 8 in this study were perceived as meeting these criteria. When all criteria could not be met, child comfort (roominess) seemed most of ten to be compromised, followed by convenience (number of operations), but perceived safety and child-containment were held firm.

Table 4 summarizes the number of times each $C R$ was selected and the distribution of positive, neutral, and negative reactions received.

\subsection{Initial Use Phase}

Most parents, including those who had never used a TCR, had little trouble figuring out what to do to instail their assigned $C R$, adjust the restraining system, and secure their child in it. Although not always properly done, the average time used was 12 minutes. This ranged from an average of 4 minutes for FTG to 25 minutes for 5599 . Average times for the others ranged from 8 to 16 minutes, but variations were more dependent on the amount of time a parent chose to take reading the instructions than on the CRs themselves.

Six parents could not find the instructions, and five asked for help at this point. Two each were working with KHR and S599. A third parent with KHR thought that "instructions inside" on the instruction cover meant "inside the box," and later commented that their actual location was certainly not very accessible. Diagrams placed on the backs of CRs were also considered useless because they could not be seen when needed during the installation process. 
TABLE 4. INITIAL CHOICE AND PRE-TRIAL REACTIONS

\begin{tabular}{|c|c|c|c|c|c|c|c|c|}
\hline \multirow{2}{*}{ Pre-Trial } & \multicolumn{8}{|c|}{ Child Restraint Models } \\
\hline & AS91 & C200 & CP78 & CP8 1 & FTG & K401 & KHR & $\$ 599$ \\
\hline Selected & 2 & 2 & 4 & 7 & 0 & 8 & 3 & 6 \\
\hline Positive & 7 & 8 & 7 & 10 & 3 & 19 & 7 & 14 \\
\hline Neutral & 2 & 11 & 6 & 10 & 6 & 5 & 6 & 5 \\
\hline Negative & 16 & 10 & 10 & 9 & 22 & 5 & 13 & 10 \\
\hline Skipped & 7 & 3 & 9 & 3 & 1 & 3 & 6 & 3 \\
\hline
\end{tabular}

Six additional parents did not even look for instructions but tried to do the job without them. Three of these anchored the CR with the vehicle belt in the wrong place, although three others made this same error with instructions in hand. All were using different CRs.

The most time-consuming task, which largely accounted for the lengthy 5599 trials, was its conversion from the packing position to upright. One of the 4 parents had used a Strolee before and had no trouble, but the other three had considerable difficulty. The interviewer had to intervene in two cases. An additional problem unique to this CR was the inability of the same three parents to adjust the harness properly, due both to the thick webbing and the continuous loop system. The latter feature also made $K 401$ difficult to fit, but to a lesser extent.

Confusion over the shoulder strap retainer led two parents to attach it behind the child's neck, while a third asked if that was where it was supposed to go. The parent using CP78 could not get it off, while the other two (S599, KHR) found it would not slide below the shoulder strap adjusters, which had ended up too high.

The most common "error" made by the parents, which, however, did not impede their progress, was making the harness straps too loose and the crotch straps too long. Parents were surprised when the interviewer told them the belts should be tighter (two fingers width of slack), but, with regard to the crotch strap, they blamed the instructions for showing high-placed buckles in the diagrams. In fact, most parents used the crotch straps just as they came from the box, although a few did 
lengthen them further. Of the samples in the study with independent crotch straps, only those on $\mathrm{C2} 00$ were packed adequately short. FTG.

Finally, the only model that was so simple it was foolproof was

\subsection{Extended Use Phase}

This section describes the experiences and reactions of parents and children to specific CRs used in their own environnents. Parents' evaluations of the instructions are reported in the last part of the section. The question of $C R$ cost was raised in each interview, but it proved to have little relevance within the framework of this study.

Some general use patterns should be noted at this time. Although actual numbers of trips were not recorded, the children in this study received varied and extensive travel exposure. Working parents took their children to day care every day, and parents doing errands put their children in and out of CRs several times in one day. Many families took long vacation trips during the study. Nearly all CRs were taken out and reinstalled in the same seat, a different seat, or a different car at least once during each three-week period. The preferred seat location was the right rear, with $40 \%$ of the usage there. All rear-seat use accounted for $77 \%$, including $14 \%$ in the center. Other percentages are included in Table 5 .

TABLE 5. DISTRIBUTION OF VEHICLE SEAT LOCATIONS

\begin{tabular}{l|c|c|c|c}
\hline Locations & All & Left & Center & Right \\
\hline Front & $23 \%$ & -- & $5 \%$ & $18 \%$ \\
\hline Rear & $77 \%$ & $23 \%$ & $14 \%$ & $40 \%$ \\
\hline
\end{tabular}

\subsubsection{Astroseat 2100B (AS91)}

Eighteen families used AS91, of which 8 were generally satisfied and 10 were not. The primary problems were with fastening the restraining system and keeping the child contained.

Installation. There were almost no problems with the wide-access vehicle-belt path. Only two parents had difficulty getting the belt tight enough. This was attributed to the belt having to make a right angle just where the buckle joins. There was also some interference with the recline lever being on the buckle side. 
Restraining System. Most parents found that the harness webbing twisted and permanently roped after a very short time. This and the inaccessibility of the harness hardware parts after the child sat on them made the system unacceptable. Adding to these problems was a wide buckle with an especially stiff buckle-release mechanism (typically 15 pounds).$^{*} \cdot$ In addition to being difficult to push, the button had to be pushed both to engage and disengage the prongs. This allowed the first prong to pop out while the second prong was being pushed in, sometimes resulting in a false latch of the first prong that then had to be checked and redone. (A warning to this effect is included in the instructions.) Still, with all the difficulties, some parents said they preferred the light weight, openness, and safety of a five-point harness.

Another problem was that the shoulder strap retainer would not stay up or could be pushed down by the child. Five children thus wiggled free of the shoulder straps. Finaliy, as cold weather approached, two parents found that the webbing itself was too short to go around their children in heavy coats. These children were less than 20 months old at the time.

Shell/Frame. Some families found ASgl sat too low, and a few thought it reclined too much in the most upright position. The shell shape was comfortable enough, but a few thought it was too narrow toward the bottom. The vinyl, of course, was hot but considered durable.

Misuse/Non-Use. One parent reported not using the harness on one occasion because it was such a "hassle," and another did likewise on a "short trip." Six parents reported not using the CR at all on at least one occasion, the reasons being short trips, the child was asleep, or the CR was not available in the car being used. Three of these parents did put their children in seatbelts instead.

\subsubsection{Century 200 (C200)}

Eighteen families used $\mathrm{C200}$, of which 16 were generally satisfied and 2 were not. The primary advantages were convenience of the restraining system and the comfortable size and shape of the shell.

Installation. Some parents had difficulty with the narrow-access vehicle-belt path, and bulky retractors would not fit at all. The same problem with the belt buckle interacting with the CR frame, as was found with AS91, existed here, making a tight belt difficult or impossible. Most parents had no problems with the installation, but a few did notice that there were no installation diagrams on this CR.

Restraining System. Nearly all parents commented on how easy it was to put this system around the child and fasten it. A few made the special point that, because there was only one thing to do, they or

* This information was not known by the parents. The forces apply to the samples in this study only and will vary from one production run to another. The tension test set-up of FMVSS 213 was not used. 
others were more likely to do it. Several also said that, to their surprise, the abdominal pad did not bother their child at all, but a few would still not use this system with an infant. A big advantage seemed to be that the system could be hung over the back of the CR when not in use and easily brought down after the child was in place. Also, the webbing never tangled.

Some parents thought the shoulder straps were too close together, making it somewhat difficult to get over their child's head. A similar number, however, thought the straps were too far apart, or that a retainer was needed, because their child could slip one or both arms out. This partial escape did not seem to concern the parents as much with this system as it did with regular five-point harnesses, perhaps because it appeared the pad alone would restrain the child.

The only real problem was that the buckle release-mechanism was too stiff (typically 13 pounds), and that, because the buckle was so wide, it was difficult to get a good grip on it when the crotch strap was very short. Consequently, several parents lengthened the strap about an inch.

Shell/Frame. Children, especially the larger ones, were very comfortable in this shell. Parents commented on its width and the cutout shape providing a place for a child's arms. The seating height was adequate, and the sides supported a sleeping child. The vinyl, while being hot, was also questioned for its durability." "Two parents said they thought $\mathrm{C} 200$ was ugly, but they would buy it anyway.

Misuse/Non-Use. There were no instances in which the child rode in C200 but the harness was not fastened. One parent inadvertently installed C200 incorrectly, putting the belt through the bottom of the frame, after losing the instructions and not having any diagrams on the CR to refer to. There were six reported cases of CR non-use, usually because the $C R$ was not available for some reason, but also because the trip was "short" or the CR was too hot to sit in. Four of the children used seatbelts instead.

\subsubsection{Cosco/Peterson Safe-T-Seat 78A (CP78)}

Sixteen families used CP78, of which 7 were generally satisfied and 9 were not. The primary problems were with the vehicle belt path, handling the harness and buckle, and keeping the child contained.

Installation. Most parents had difficulty getting the vehicle belt webbing in the belt-guide slots and then tightening the belt. The buckle usually ended up right at the guide, so that the belt had to be left too loose or the guide not used. The one advantage was that bulky retractors could be fed through this wide-access path, although the same buckle/frame interaction problems occurred.

Restraining system. Twisting and roping of the harness was again a problem, as was the inaccessibility of the hardware parts as the child was being fastened in. The stiffness of the buckle-release mechanism was acceptable (typically 8 pounds), but the two parts were hard to hold 
together while engaging the prong in the buckle. A few parents, however, found this "one-prong" buckle less trouble than two prongs.

The shoulder strap retainer received mixed reviews. Although some said it was good because it stayed up, others found their children could remove it and thus free their arms. Being completely removable, it also got lost. Finally, the parent of a 2-year-old found the straps were too short to go around her child in a heavy coat.

Shell/Frame. The shell was reasonably comfortable, especially for sleeping, but a few families thought it was too low. The vinyl was nicer than the others, but still hot. CP78 was generally considered a "good looking" CR.

Misuse/Non-Use. On three occasions, parents did not fasten the harness, because they were "very short" trips or the parent was making "many stops." Five cases of CR non-use were reported, again because of short trips, the CR not being available, and the heat, but also because there was no room in the car. Three of the children used seatbelts instead.

\subsubsection{Cosco/Peterson Safe-T-Shield BiA (CP81)}

Twenty families used CP81, of which 8 were generally satisfied and 12 were not. Two families brought it back early. The primary problem was with child comfort, although the restraining system was very easy to fasten.

Installation. Most parents used the high narrow-access belt path, avoiding the belt-guide problem of CP78. Some still had difficulty tightening the belt, as with AS9l and C200, but for most parents, installation was not a problem. A few did comment that CP81 was very bulky and heavy to carry from car to car.

Restraining System. Nearly all parents said they found the shield extremely easy to fasten and adjust, but several had other handiing problems. The low roof-line over the rear seat of some cars did not allow the shield to stay up on its own when the child was going in or out. It was often difficult to maneuver the child under the shield and to keep it from hitting the child's head on the way up or down. Some parents found it difficult to pull both buttons simultaneously, especially when reaching into the rear seat of a two-door car. One child discovered, much to the parents' dismay, that pushing up and down on the engaged shield made a terrific rattling noise.

The major problem, however, was the geometry of the shield/shell combination in relation to the child. Most children required the loosest adjustment notch, and the rest could use the second notch. These positions placed the shield relatively high in front of the child, as is necessary for this type of restraining system, while still being quite close. Children could not, therefore, rest their arms on their lap, nor could they put their arms to the side because the sides of the shell were also close. The only place for hands or arms was thus up high on top of the shield. After being in CP8I for longer than 15 
minutes, the children in this study did not like that arrangement at al1. In fact, none of the families who took this CR on a long trip considered it satisfactory. Despite the relative confinement provided by CP81, however, three children managed to climb out when the shield was in the loosest position, and one child weighing 25 pounds partially slid under it.

A related problem was that the height of the shield blocked the child's view. To solve both these problems, several parents tried boosting smaller children with a pillow as recommended in the instructions, but the results were satisfactory only about half the time.

Shell/Frame. The problem with the close, wrap-around shell in combination with the shield has been noted. On the positive side, CP81 did seem to be comfortable for sleeping, with several children resting their heads forward on the shield. The cloth upholstery was also regarded as very attractive and comfortable, but many also had reservations about their ability to keep it clean.

Misuse/Non-Use. The most drastic case of misuse occurred with CP81, when one parent gave up using the shield altogether, first trying to remove it, but settling for swinging it over the back of the seat and putting the vehicle belt over both $C R$ and child. In another case, a third party unfamiliar with the $C R$ installed the belt incorrectly. The four reported cases of non-use involved lack of space, being without the CR, and a fussy child. Two of these children wore seatbelts instead.

\section{3 .5 Ford Tot Guard (FTG)}

Sixteen families used FTG, of which 4 were generally satisfied and 13 were not. Four families brought it back early. The primary problems were with child comfort and keeping the child contained. Among the satisfied families, all children were over 2 years old at the beginning of the study.

Installation. Most parents had no trouble installing FTG, al though a few had belts that were barely long enough. Although light in weight, a few said FTG's two pieces were awkward to carry and hard to hold onto when moving from one car to another.

Restraining System. Most parents found the CR quite easy to use, especially if the child could both get in and out without the shield having to be removed, as about half of them could. (Some others could get in but not out, and vice versa.) Even having to rebuckle the shield each time, however, was not considered much of a disadvantage. But two children, who were capable of wiggling out with the shield in place, regularly reached down and undid the vehicle belt once the family arrived at its destination, much to the parent's annoyance. One parent solved the problem by turning the buckle over so the child could not get at the release button.

The major problem for parents with children who could get out unassisted was that they often did so when the car was moving. This was 
a problem for half the families that tried this CR. One child weighing 28 pounds slipped under the shield when the cushion was in its lowest position. Another problem, particularly for the smaller children, was that they could not see over the shield, even with the cushion in its highest position. A few parents were concerned that FTG might not be safe, because it had no straps and no side structure.

Shell. The lack of side support for the head was a problem for the sleeping child. Only one rested his head comfortably on the shield. Some parents also thought FTG looked uncomfortably hard and cold.

The lack of straps and side structure was a great advantage for two families of older children, in that the children reacted positively to their new-found freedom and behaved better than in more restrictive CRs. Another older child with a history of good CR behavior expressed his enjoyment of FTG and would have liked it for his own, but he squandered his freedom and lost his prize.

Misuse/Non-Use. Two parents used the booster cushion without the shield but with the vehicle belt over child and cushion. One case was due to the child being unable to see and the other due to insufficient belt length in a friend's car. Four reported non-use occasions involved short trips, child discomfort, and CR unavailability. Three of these children wore seatbelts instead.

\subsubsection{Kantwet One-5tep 401 (K401)}

Seventeen families used $\mathrm{K} 401$, of which 10 were generally satisfied, 4 were satisfied except for the tether, and 3 were not. The primary advantage was convenience of the restraining system, while the major problem was the tether.

Installation. Remember that the assumption that tethers are inconvenient was made at the beginning of the study, and that families could choose not to use any tethered CRs. But among these willing families, many found the tether impractical because it severely limited the seat location or the car in which the CR could be used. Those who tethered it to a rear seatbelt also lost a seating position. Some found the tether was too short in its normal "doubled" configuration and was very difficult to get tight in the longer single configuration.

There was little difficulty with the vehicle belt path, but a few buckles again hit the frame at just the wrong place. Two families with loose-belt problems appreciated the extra security of the tether.

Restraining System. Most parents found the restraining system very easy to handle. The single-prong buckle and easy harness adjustment system were especially noted, again making them more likely to be used. Some did say the buckle-release mechanism was too stiff (more variable than other CRs, but typically 12 pounds), that the buckle and adjusters were hard to see, that the continuous shoulder-strap/crotch-strap configuration was difficult to orient properly, and that the child's arms sometimes got caught under the shield arms. The spring mechanism was viewed as an advantage in getting the child in and out, but as a 
disadvantage in that one must refasten it when the $C R$ was not in use, lest the elevated shield block the driver's view. Although the shield was too tight for some larger children, it was a nice "tray table" for others. Four children freed their arms or shoulders from the straps, but, as with 6200 , parents were not very concerned, perhaps because the partial shield was still there and appeared to be able to hold the child in.

Shell/Frame. The seating height of $K 401$ was considered somewhat better than average, and the shell seemed to provide adequate room and was comfortable for sleeping. The vinyl again was hot, and several parents questioned its durability.

Misuse/Non-Use. There were no cases in which children rode in $\mathrm{K401}$ when the restraining system was not fastened. Two families did not anchor the tether, however, on one or more trips. In one case there was no anchor for rear-seat use, and both parents wanted to sit in front on a long trip. In the other, there was no tether anchor in the second car, and, although the parent put the CR in front, he did not attach the tether to a rear belt. Then, to supposedly make the CR more secure, the parent routed the belt over the front of CR and child. Four cases of reported non-use involved child resistance, short trips, and lack of a tether anchor in a second car. Three children wore seatbelts instead. The two children who resisted $K 401$ were older children who used it late in the study and had already selected another $C R$ as the one they wanted their parents to choose.

\subsubsection{Kolcraft Hi-Rider (KHR)}

Fifteen families used KHR, of which 6 were generally satisfied and 9 were not. The primary problems were with the vehicle belt paths and use of the shield. Two families could not satisfactorily install KHR and used it only briefly.

Installation. Most parents chose not to use the optional partial shield and thus fed the vehicle belt through the shell's narrow slots. Others would have used the shield, but their belts were not long enough to go around $i t$. All found the through-shell path much more difficult to use than any through-frame path. The slots were not visible from the side, some buckles just barely fit, and others ended up right at the slot or uncomfortably hitting the child's back. Bulky retractor buckles, of course, would not $f i t$ at all.

Restraining System. Several families tried the shield at one time or another, but nearly all found it too confining for the child and too difficult to snap in place. Thus KHR was generally used as a five-point harness system that had too many adjustments and no particular advantages except, for some, a very easy buckle. The buckle was so easy, in fact, that one family had to go back to using the shield to keep the child from opening it. Two children, including this one, completely disengaged the buckle, another freed his arms from the shoulder straps, and one child pushed the shield off when the vehicle belt was in place. 
Shell/Frame. The shell by itself was considered comfortable and good for sleeping. Several parents commented on the high seating level and the cloth upholstery. Only one parent thought it was too reclined in the upright position. Although more appropriate later, the location of the instructions was so unusual that a mention should be made here. Some parents said they would have liked to refer to the instructions at one time or another, but they were so inaccessible (a screwdriver was usually needed to get the lid off) that they did not bother.

Misuse/Non-Use. One of the parents in a couple never used the harness but used the partial shield by itself. This parent was convinced the shield alone was safe enough. Later, upon discussing the system with the interviewer, he was convinced otherwise. Six cases of non-use were reported, two because KHR involved too much of a hassle to install in another car or to secure the child. Other reasons included lack of room in the car, short trips, and a sick child. Five of these children wore seatbelts instead.

\subsubsection{Strolee Wee Care 599 (5599)}

Fifteen families used S599, of which 7 were satisfied and 8 were not. The primary problems were with the complexity of the restraining system. The major advantage was its seating height.

Installation. This group of parents was more tolerant of the tether than the group using $\mathrm{K} 40 \mathrm{l}$, partly because the tether adjustment was easier to use. Some parents still commented that the tether limited CR location, but perhaps the associated extra height was an acceptable trade-off.

There were no problems with the vehicle belt path nor any mismatches with buckle locations, due again to a higher frame structure. One parent especially appreciated the belt diagrams being on the side where they could be seen.

Restraining System. Most parents found the restraining system objectionable in some way, particularly the number of operations that had to be performed and the difficulties in adjusting the harness. The latter was due first to thick webbing being threaded through hardware that was too small for $i t$, and second to the continuous loop harness arrangement that was difficult to rotate and orient properly. The stiffer harness still twisted, but not as badly as the others. Parents did like the buckle's small size and relatively easy release (typically 11 pounds), although it did have two prongs.

Although the arm rest was not necessary to the restraining system (parents were told this), it still had to be dealt with when buckling in the child. Several said they would have preferred it not be there. In cars with low roofs, the arm rest made child access difficult, and being spring loaded it had to be buckled down so that it did not obscure the driver's view. Children's arms also got caught under it, and it made the buckle difficult to see. A few did say their child liked the "tray table," or that it was a good place to sleep. No one thought it was confining. 
Shell/Frame. Most parents commented on the extra seating height and felt their child was happier being able to see better. One parent, however, said the CR was so high it blocked the driver's view. A few said the shell was too narrow for their child, or too upright for comfortable sleeping. A few children were also too short to take advantage of the high-placed side head rests. The cloth upholstery was considered attractive and comfortable.

Misuse/Non-Use. Two parents did not use the harness on isolated occasions. One, a very safety-conscious parent, just could not get the harness adjusted in the dark to the child's new coat. The only solution was to fasten one side to hold the arm rest down and hope for the best. in the other case, the parent said it was too much trouble for a short trip. Of six reported cases of non-use, three were because a tether anchor was not available, and the others because of buckling hassles, short trips, and a sick child. Four children used seatbelts instead.

\subsubsection{Evaluation of the Instructions}

Most parents took the time to read each set of instructions and provide some comments. Many parents took considerable care with their evaluations. The following is a compilation of their comments along with some additional observations: Instructions for the CRs are treated as a group, because the major problems were common to several or all of these examples.

Format. Good diagrams along with explanatory text were considered essential. The dark photographs of KHR were nearly useless and mislabeled as well. FTG, CP78, and CP81 had the best diagrams, but their print and that of 5599 was too small. Most of the typography and layout looked "professional," thus inspiring confidence, with KHR and AS9l being the exceptions. The single sheets were much preferred over FTG's multiple-sheet format.

Scare Tactics. Warnings about failure to follow instructions exactly, a direct consequence of FMVSS 213, were too severe. Conscientious parents agonized over insignificant details (such as whether the tether hook should be up or down) for fear they would compromise their child's safety. At the same time, information that would have been useful to a parent for making intelligent decisions was left out. Many parents wondered why it made any difference which direction one threaded the harness webbing through the buckle-prong slots. Others wondered if the belts they had installed themselves were not safe after all, since instructions refer to "factory installed seatbelts only." Another wanted to know why one was not supposed to adjust the reclining mechanism while the child was in the CR. One parent became quite anxious after discovering the direction "engage last" imprinted on one of the KHR buckle loops, and he was disturbed that nothing was mentioned in the instructions. In fact, there was no mention made of the buckle at all. Finally, several parents asked what to do if they did not have seatbelts in the center of their back seat. 
Confusion and Misinformation. Having generated a level of fear, the instructions then used jargon and undefined terminology that most parents do not understand. Examples mentioned were:

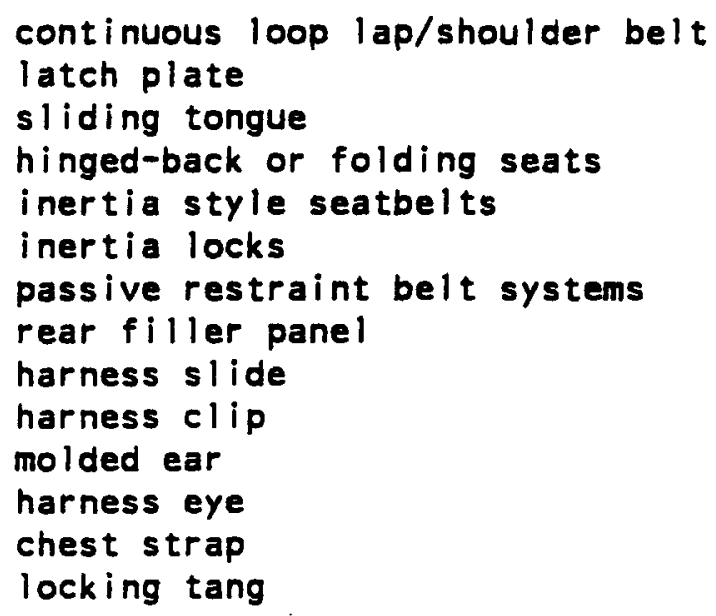

The greatest amount of confusion was over whether or not a parent needed a "locking clip." Although admittedly difficult to describe while covering the company legally, the tendency was to describe too broad a situation as "needing" a locking clip, to make the descriptions dependent on a knowledge of the above jargon, and to omit the actual reason a locking clip may be needed, i.e., to tighten a potentially loose system so that the CR does not tip or shift out of position in transit. Examples follow from the instructions in order of increasing clarity and usefulness (emphasis ours):

For use in seating positions equipped with inertia style seat belts, a special locking clip is necessary to hold your car seat in place. . . (C200)

Locking clips are recommended for continuous loop seat belt systems. (5599)

Some cars have, for the right front seats, a continuous loop lap/ shoulder belt which requires an optional locking clip to securely tighten the lap belt section. (CP78)

Some cars have latch plates with a slotted attachment that lets the latch plate slide along the belt. This type system does not hold the child seat securely and requires a locking clip. (CP81)

If used in a vehicle seat with a continuous-loop lap/shoulder belt system with a sliding tongue (i.e., the lap belt does not maintain a snug $f i t$ when tightened and can be loosened by pulling on the belt), a locking clip must be installed on the belt system. (AS91)

Do not use the [CR] with any lap-shoulder belt system which allows the webbing to slide freely thru the latch plate in both directions when the belt system is fastened unless a locking clip is used. (K401) 
FTG devoted a full page to the locking clip and depended on excellent diagrams to explain the hardware referred to. Although still too broad in application, it did provide parents with the best visualization of what the locking clip was all about and how it was used. KHR did not mention the issue at all.

As mentioned before, diagrams generally showed crotch straps too long, and thus buckles appeared at the child's waist. Only C200 did a proper job. While $\mathrm{C} 200$ did include the written information that crotch straps should be as short as possible, this was included only for rearfacing use, when it is not so important, and not for forward-facing use. Having been told that safety was somewhat reduced in the reclined position, parants questioned the suggestions made in two sets of Instructions that, If the shield did not clear the roof (CP81) or the vehicle belt were not long enough (KHR), the CRs be recllned. Parents were also concerned that S599's arm rest was referred to as "ohield," which might lead parents to think it was a necessary part of the restraining system.

One parent thought the diagram showing a child in CPBI was misleading in that the shield was portrayed much lower and thus more comfortable than it was in reality. The diagrams and explanations of the alternate belt routes were also unclear, and there was some confusion as to whether FTG had to be used with a shoulder harness, because of a prominent color photograph showing it in the front seat.

Finally, the easier the CRs were to use, the easier the instructions were to follow, although some thought CP81 and FTG instructions were more complicated and wordy than necessary. A few suggested that parents were well advised to take the 5599 advice to "reread these instructions."

Omissions. None of the instructions for forward-facing use mentioned that crotch straps should be as short as possible to pull the lap straps low over the thighs or the partial shields down in front of the pelvie bones. (5599 did say the "lap belt" should be low but does not say how to accomplish this, and many parents indeed had diffleulty.) This is only true, of course, for toddlers facing forward, and the suggestion could be made that crotch straps can be lengthened for convenience with rear-facing infants.

Parents noted that 5599 did not include a diagram of the doubleslide harness adjustment system, and C200's single-slide drawing was very poor. Several parents suggested it would have been helpful to state that the pushbutton buckles can be more easily engaged if one pushes the release button while inserting the prongs.

Parents were both amused and annoyed that cleaning instructions were included for all the vinyl CRs but for none of the cloth-covered ones. With cleanability an unknown, many would be reluctant to select a cloth CR. We and they found that mild soap and water was usually sufficient, but not for everything that children handle. Some guidelines are definitely needed. 
CR/vehicle incompatibilities presented such a problem for some parents that the suggestion was made that known problens for a particular CR be outlined in the instructions, or better yet on the box. This would help parents not only in selecting an appropriate CR but also in making them more confident about returning mismatched products.

Helpful Information. Parents appreciated the suggestions common to most instructions to cover the $C R$ to guard against burns. Also mentioned were a warning not to use the CR again after a crash (AS91), a recommendations that the $C R$ be buckled in when not in use, and the suggestion that parents should set a good example (CP78/CP81).

K401 was the only one to address the buckle-force issue, and the explanation was appreciated. $\mathrm{C} 200$ and $\mathrm{K4OI}$ included useful guidelines for how "snug" to adjust the harness. CP78 included a good explanation of how to know when the shoulder straps should be raised to the upper slots, although the reason given was incomplete. The tether instructions of 5599 were considered very well-done and complete, while K401 was inadequate by comparison. Finally, lists of replacement parts were appreciated, especially when they included prices.

Summary. Most instructions were considered adequate, but jargon and dire warnings without sufficient explanations weakened their effectiveness. Writers of instructions should take greater care that the information they include is complete as well as accurate. The parents evaluating these instructions were not an average cross-section. For less motivated or less well-educated parents, these instructions might be formidable.

\subsection{Final Choice Phase: Post-Trial Opinions}

Opinions and concerns volunteered by the parents.are again grouped into three categories: safety, comfort, and convenience. Comparisons with pre-trial opinions are implied. Table 6 presents the actual pre- and post-trial tabulations along with the number of parents who voiced the same opinion at both times (overlap).

\subsubsection{Safety}

Child containment was still important to several parents (9), especially formerly dissatisfied users, but this criterion had lost some verbal support. Four parents said they now preferred having a tether. No one mentioned any safety advantages of an SIF.

\subsubsection{Comfort}

Half as many parents mentioned the height requirement, and largely from a different group, but support for a wide, roomy shell nearly tripled. More parents mentioned an objection to confining shields, but again from a shifted population, and fewer said they wanted a "tray table." The need for a side head-rest gained support, while the appeal of cloth upholstery plummeted. 
TABLE 6. COMPARISON OF PRE-TRIAL ANO POST-TRIAL OPINIONS

\begin{tabular}{|c|c|c|c|}
\hline Factors & Pre-Trial & Over lap & Post-Trial \\
\hline $\begin{array}{l}\frac{\text { SAFETY }}{\text { SIF }} \\
\text { Child Containment } \\
\text { Tether }\end{array}$ & $\begin{array}{r}13 \\
13 \\
1\end{array}$ & $\begin{array}{r}0 \\
7 \\
-\quad 0\end{array}$ & $\begin{array}{l}0 \\
9 \\
4\end{array}$. \\
\hline $\begin{array}{l}\text { COMFORT } \\
\text { Height } \\
\text { Width, roominess } \\
\text { Shield confining } \\
\text { Tray Table } \\
\text { Side head rest } \\
\text { Cloth }\end{array}$ & $\begin{array}{r}13 \\
6 \\
13 \\
11 \\
2 \\
18\end{array}$ & $\begin{array}{l}2 \\
3 \\
5 \\
4 \\
0 \\
4\end{array}$ & $\begin{array}{r}7 \\
16 \\
18 \\
6 \\
6 \\
5\end{array}$ \\
\hline $\begin{array}{l}\text { CONVENIENCE } \\
\text { Easy restraining } \\
\text { system } \\
\text { No tether } \\
\text { Easy installation } \\
\text { Vinyl } \\
\text { Durability }\end{array}$ & $\begin{array}{l}20 \\
6 \\
2 \\
9 \\
7\end{array}$ & $\begin{array}{l}17 \\
3 \\
0 \\
3 \\
3\end{array}$ & $\begin{array}{r}26 \\
18 \\
9 \\
6 \\
6\end{array}$ \\
\hline
\end{tabular}

\subsubsection{Convenience}

A quick and easy restraining system was stlll the dominant factor (26), but not wanting a tether was expressed by three times the pretrlal number of parents. Ease of installing the CR and switchlng it from car to car was now important to several parents (9). Fower parents mentloned they wanted vinyl upholstery, but the number concerned about durablllty remained about the same.

\subsubsection{Post-Trial Selections}

The single most popular model, which was now perceived by parants who used it as combining the most popular features, was 6200 (16 selected). Ease of use was the primary factor, but thls had to be combined with child comfort. The latter related both to shell size and shape and to the non-confining partial shield. The lack of a tether was mentioned next often, and ease of installation was implied. A faw mentioned the side head rests and that their child could not get out. Apparently parents were willing to put up with the "cheap" vinyl and ungainly appearance. The only reservation expressed was that the abdominal pad would not be suitable for an infant, but only one family had a chance to try it that way. All but two families who selected C200 
had used it in the study, but none had selected it originally. It is interesting that nearly all the parents who had not used 2200 still expected the restraining system to be uncomfortable for the child and expressed this in the final interview. Although given the opportunity, most of these parents did not even want to try it.

The next popular model, for many of the same reasons, was K401 (7 selected). Its primary drawback compared to C200 was the tether and secondarily the less roomy space for the child. For half of those who chose it, however, the tether was a plus. The "tray table" for the child was also mentioned. All 7 families had used $\mathrm{K} 401$ in the study, and two had selected it originally. This was the only CR that was generally popular in both pre-trial and post-trial selections and overall satisfaction.

For a few families, FTG was a unique CR that fit both the parents' and child's needs well ( 3 selected). All children were over two years old. Its ease of use, accommodation of a larger child, and feeling of freedom were all important. All 3 families had used FTG in the study, but none had selected it originally. At the first interview, one of these parents even said, "I'll drop out of the study if I get this one!"

The most popular $C R$ with a five-point harness was CP78 ( 3 selected). Aside from the preference of these parents for this type of restraining system, they liked the smaller buckle and found the system kept their child contained. One parent would have preferred a belt path without the narrow "guides." All 3 families had used CP78 in the study, and one had selected it originally.

Of the remaining four models, one family each selected AS91, CP81, and KHR. S599 was not selected. All 3 families had used the chosen CR in the study, but none had selected it originally. AS9l was chosen for its five-point harness and child comfort. CP81 was chosen for its ease of use in spite of some reservations about child comfort on a long trip. KHR was selected for child-comfort reasons. It was the highest CR without a tether, had a cloth cover, and would be, used without the shield. The parent would have preferred a different buckle and belt path, but comfort was paramount. For the final choice, 5599 suffered both from its tether and its complex buckling arrangement. Apparently its extra height did not provide a sufficient trade-off after all.

\subsubsection{Summary of Final Choice Phase}

Parents selected CRs that they knew to be satisfactory and in most cases marvelous, because they had used them. An acceptable CR had to be both comfortable for the child and easy for the parent to deal with. In only two cases was the child's preference, or perceived preference, subordinated to the parents', and both were at least partially for child containment reasons. There was virtually no correlation between pretrial and post-trial selections.

Table 7 summarizes the number of times each CR was selected and the distribution of general satisfaction and dissatisfaction expressed in the extended use phase. Table 8 shows the scatter of pre-trial versus 
post-trial selections. The dots in the shaded area represent the three cases when pre-trial and post-trial selectlons were the same.

TABLE 7. FINAL CHOICE AND POST-TRIAL REACTIONS

\begin{tabular}{l|cccccccc}
\hline \multirow{2}{*}{ Post-Trlal } & \multicolumn{7}{|c}{ ChIld Restraint Model } \\
\cline { 2 - 10 } & AS91 & C200 & CP78 & CP81 & FTG & K401 & KHR & 5599 \\
\hline Selectad & 1 & 16 & 3 & 1 & 3 & 7 & 1 & 0 \\
\hline Satisfled & 8 & 16 & 7 & 8 & 4 & 14 & 6 & 7 \\
\hline Dissatisfled & 10 & 2 & 9 & 12 & 12 & 3 & 9 & 8 \\
\hline
\end{tabular}

TABLE 8, PRE-TRIAL VERSUS POST-TRIAL SELECTIONS

\begin{tabular}{|c|c|c|c|c|c|c|c|c|}
\hline \multirow{2}{*}{$\begin{array}{l}\text { PRE-TRIAL } \\
\text { SELECTIONS }\end{array}$} & \multicolumn{8}{|c|}{ POST-TRIAL SELECTIONS } \\
\hline & $\stackrel{\text { AS91 }}{(1)^{2}}$ & $\begin{array}{l}C 200 \\
(16)\end{array}$ & $\begin{array}{c}\text { CP78 } \\
\text { (3) }\end{array}$ & $\begin{array}{l}\text { CP81 } \\
\text { (1) }\end{array}$ & $\begin{array}{l}\text { FTG } \\
(3)\end{array}$ & $\begin{array}{c}\mathrm{K} 401 \\
(7)\end{array}$ & $\begin{array}{l}\text { KHR } \\
(1)\end{array}$ & $\begin{array}{c}5599 \\
(0)\end{array}$ \\
\hline $\begin{array}{c}\text { AS91 } \\
\text { (2) }\end{array}$ & & & & & & - & - & \\
\hline $\begin{array}{c}C 200 \\
(2)\end{array}$ & & & - • & & & & & \\
\hline $\begin{array}{l}\text { CP78 } \\
(4)\end{array}$ & & & 3 & & & & & \\
\hline $\begin{array}{c}\text { CP81 } \\
(7)\end{array}$ & - & $\bullet \bullet \bullet$ & & & - & $\bullet \bullet$ & & \\
\hline $\begin{array}{l}\text { FTG } \\
(0)\end{array}$ & & & & & & & & \\
\hline $\begin{array}{c}K 401 \\
(8)\end{array}$ & & $\because \bullet$ & & & & 08 & & \\
\hline $\begin{array}{l}\text { KHR } \\
\text { (3) }\end{array}$ & & & & & & 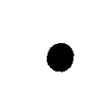 & & \\
\hline $\begin{array}{c}5599 \\
(6)\end{array}$ & & $\bullet \bullet$ & & 0 & - & Q & & \\
\hline
\end{tabular}




\subsection{DISCUSSION}

Two related phenomena occurred in this study. First, thirty-two families, nearly half of whom had previously selected a TCR with which they were not satisfied, were able to select a new one with which they were very satisfled. Most of the families, former users and non-users alike, could even be said to be enthusiastic about their new CR. Second, nearly all the families would again have not made the best choice for them if they had not been educated by their own experiences and by factual information provided in the study.

Although there is a wider range of CR designs available today than ever before, this situation does not seem to make it any more likely that consumers will choose the one with which they will be the most pleased or which they will use the most conscientiously. In fact, the variety of designs may add to the confusion and make the decision process more difficult. Consumers need help.

To shed some light on what help is needed, the following discussion addresses the changes that occurred during the course of this study in $C R$ selection criteria as well as in parents' perceptions of what meets these criteria. We then try to provide some insight into why CRs are designed the way they are and to identify consumer information gaps that need to be filled. Finally, we discuss the apparent causes of misuse and non-use and relate these to the above topics.

\subsection{Changing Criteria and Perceptions}

Over the course of the study, parents gained new information that made them adjust and sometimes significantly change the criteria they used for selecting a CR. At the same time, they learned that CRs $f i t$ some of their criteria differently than they expected. The differences were so dramatic that parents refused to permanently select a CR that they had not had a chance to use. In addition, satisfaction with a given $C R$ was somewhat dependent on which other CRs a family had also used.

\section{1 .1 Safety}

Parents were very receptive to new information regarding SIFs. We explained that the basic restraining system was a five-point harness that holds a child back at the pelvic bones and shoulders. The head then hits nothing at all, which is softer than any "something." SIFs can then be grouped according to how much of the five-point harness they are designed to replace. Arm rests replace nothing and are thus not part of the restraining system. Partial shields usually replace the lap portion of the harness. Full shields replace the entire harness and thus need no straps at all. SIFs can have advantages other than crash protection, such as being convenient or giving a child pleasure, but it is important to understand their different functions so the consumer knows what $s /$ he is paying for.

The function of the tether and the need for it on certain models was explained. We tried in addition to provide some perspective on 
crash rlsk by advising that, if properly Installed and snug around the child, a CR that needs no tether provides as much protection as would be needed in nearly any crash that might occur, particularly if used in the back seat. We also emphasized, however, that just because a CR did not need a tether to meet federal Standards, there was no reason why a tether could not be added to most models if the parents preferred the extra potential head protection. Most parents already understood that extra height usually signaled the need for a tether. With this background in mind, some parents' attitudes toward tethers changed or solidified with actual use experience. A few became committed to tethers, but most parents decided against them.

The dependence of safe installation on CR/vehicle compatibility was a problem no parents had anticipated. Although some CRs could not be installed at all in certain cars, the more frustrating situation involved belt buckles that hit the CR just at the wrong place. Parents then had to spend considerable time and energy working the beit into a tighter configuration. Sometimes the belt could not be tightened to an acceptable level. It may be asked whether CR designers or vehicle manufacturers are the appropriate ones to address this widespread problem. One change in CR design that was suggested was to move the recline mechanism on many CRs to the right side, because most belts in the recommended center and preferred right-rear positions buckle on the left.

Child containment became less of a problem for three reasons. First, the new designs did a better job of keeping the child in than the old harness/buckle systems. Shoulder straps, particularly on the partial-shield/harness combinations, seemed to stay in place better, and the new pushbutton buckles were impossible for children to open. Second, parents learned that harness straps needed to be tighter than they had been making them. Third, the children all found a CR they liked and were comfortable enough in to want to stay in. An interesting final observation was that parents who had essentially no experience with TCRs did not even anticipate that child containment might be a problem.

\section{1 .2 Comfort}

Chlldran as young as 12 months have and express preferences for cartaln CRs and disllke for others. By age two, many parents find they are foresd to et least take these proforences into conslderation. We have found that chlld discomfort and dissatlsfaction wlth cortaln CRs is real and can result in considerable dispuptive behavior, Ineluding screaming and trying to escape from the CR. The same chlldren in the right CRs, however, ean become smiling little angels who do not even try to free themselves, as some of them still could. Many parents commented on the amazing change in their child's disposition and behavior once s/he had found "my car seat." One could argue that some of these children's pleasure was derived from the sheer novelty of the experience and the attention they were getting, as may have contributed to the effect observed by Christophersen." In a few cases with older children, however, the children made their decisions early in the study and were unhappy in subsequent CRs. 
To their surprise and chagrin, parents were quite unable to predict in which CRs their children would be comfortable and well behaved. Shields that looked nice turned out to generate considerable discomfort and resistance, while others that looked unacceptable turned out to be just what the child wanted. Only actual experience could tell. The most important variable seemed to be freedom of movement for the upper arm, with restriction of the upper torso being much less important. This critical shoulder-to-elbow space can be affected by side structures, front structures, or a combination of both. The worst possible case occurs when the range of arm movement is restricted both by a side wall and a close-fitting shield. The best case has neither of these restrictions. Thus, even if there is no shield, the width and shape of the shell are important factors.

Nearly all CRs are too narrow for the size children they claim to accommodate. It is clear that anthropometric data have not been used in determining needed width (or harness webbing length), nor has the additional consideration of heavy clothing been taken into account. CR size may be a major factor in the marked drop in CR use with age among children still under age 4, 40 inches, and 40 pounds. Parents in this study were not particularly sensitive to shell size in their initial perceptions, but they soon discovered its importance, particularly for older children.

Being able to see out the window seems to be important both for entertainment and learning purposes, and this is a major advantage for both parent and child of having any $C R$ at all. One parent described how happy the child was to be able to see something other than the tops of the trees. The question is, how much height is enough? A few complaints were made about the lower CRs, especially if they had a greater than average back angle, but $4-1 / 2$ to 6 inches of elevation seemed to be adequate. If further height could be achieved without a tether, it would probably be well received, particularly for younger children.

Another vision problem involves obstruction by the CR, but more so in front than to the side. Parents sometimes expected their children would have difficulty seeing when in fact they did not. When their view was blocked, however, children became very anxious and of ten tried to get out.

Child comfort and satisfaction was very important to the overall satisfaction of a family with a CR. Because a child who is difficult to handle makes the $C R$ difficult to handle, the child's comfort actually became a major factor influencing ease of use. We continue, however, with the more mechanical aspects of convenience.

\section{1 .3 Convenience}

Having an easy-to-use restraining system was a strong preference initially that was reinforced during the study. The new information gained by the parents was just how easy it could be compared to what they were accustomed to using. Most parents could evaluate ease of use in the "showroom," but there were a few surprises once they put some CRs 
in their cars. These involved difficulties with low rooflines and with spring-loaded SIFs that, when left up, blocked the driver's view.

There were many factors that made a restraining system easy to use. The child's acceptance of it has been mentioned. Bayond thls, it was convenient to be able to put the restraining system completely out of the way while the chlld climbed or was put in and out, and it was a bother to have to re-engage it when unoccupied. A fastening aystem using only: single prong or other engagement device was nearly ideal. Not having to fasten anything at all was even better. Inconvenlence, and thus admitted Ilkellhood of non-use or misuse, increased directly with the number of operations that had to be done. The fewer and more obvious the operations, the more likely that third parties would be able to use it correctly as well, even without any explanation. For these reasons, two-prong buckles, shoulder strap retainers, and extra SIfs were viewed as inconvenient and otherwise undesirable.

Some inconveniences were accepted by parents in this study as inevitable and did not really affect overall satisfaction. Nearly all harness adjustment systems presented were not particularly easy and would probably have caused more annoyance if the weather had changed during each use-period. A double-slide system seemed to have the best potential, and placement of any adjuster on the front of the system was preferred. There still seems to be considerable room for jmprovement in the basic design of these systems, however.

Parents did not like the stiff buckle-release mechanisms, al though some initially thought their child could open them. In fact, no child opened a pushbutton buckle, including the easiest one, while some did undo the Waterbury type. Among the pushbuttons, however, the narrower ones were easier than the wider ones for parents to get enough leverage, and thus they were preferred.

Installation proved to be more of a cholce-limiting factor than a matter of convenience. If the CR could not be installed satisfactorily or at all. it could not be used. Beyond that and the tether issue, installation ease was of lower priority than comfort and restrainingsystem ease in the final choices. The type of upholstery, either for appearance or durability, aiso became quite unimportant in the end, but improvements in materials and choices among them would probably be appreciated.

To emphasize again the relative importance of comfort versus convenience, some parents said they were willing to put up with any restraining system as long as the child liked it.

\subsection{Influences on Child Restraint Desion}

Aside from the overriding goal of providing chlldren with a safe ride, there are two major factors that influence CR design: marketplace experience and FMVSS 213. Although this discussion is not intended to be exhaustive, we do try to raise some issues that are relevant to longterm CR satisfaction that deserve further attention. 


\subsubsection{The Marketplace}

Consumers have a history of thinking that some kind of structure in front of the child, no matter how far away or narrow, is a necessary feature of a CR, and they want it not for comfort but for safety. It is difficult to determine, however, whether parents are thinking more in terms of crash protection or merely of keeping the child in place. The origin of this misperception may be rooted in the original car seat designs that had nothing but a bar; or it may be a transfer from other child furniture, such as high chairs. There is even a possibility that parents think their children can brace themselves and hold on in a crash, just as parents think they can hold onto their children. Whatever the reason, there is a firm conviction among marketing people that a CR must have an SIF to sell. An executive of a major retail chain has even been quoted as saying that he would not stock any child restraint that did not have a "shield."

The first problem that results is that designers are increasingly being limited to systems that include SIFs, thus taking creative energies away from potential improvements in harness-only or other innovative systems. Inertia locking retractors and recessed buckles have been tried, for instance, with harness/shield combinations. Why not use them to counteract the various complaints consumers have with five-point harnesses? The second problem is that, while shields can be very effective in a crash, there is usually a conflict between comfort and effectiveness. After actual use, the consumer may find that an effective shield is uncomfortable or, conversely, assume that a comfortable partial shield or arm rest is effective by itself. The third problem is that CRs that "sell," if they are not also comfortable and convenient, may in the long run hurt the entire effort to get children into restraints.

Prior to the introduction of any new product, it is typically "test marketed" to see what consumers think of it. Why then do CR designs make it to the shelf that prove with later use to be unsatisfactory? In fact, most CRs in this study received several satisfactory evaluations, even though some were not of ten selected in the final choice. Also, different families certainly have different needs and preferences, so that a wide range of choice is good for consumers. We suspect, however, that marketing decisions are made based more on appearances, brief impressions, and/or use of one or two designs in isolation from others. Without an opportunity to compare different designs in their own use environment, consumers really have a difficult time knowing what works and what does not. We know of one manufacturer who solicits a brief user-evaluation form from purchasers. Although this procedure has obvious shortcomings, we think the effort's value has shown itself in the design of and modifications to the product. We encourage others to do likewise.

\subsubsection{FMVSS 213, Child Restraint Systems}

The new FMVSS 213, with additional incorporated sections from FMVSS 209, Seat Belt Assemblies, and FMVSS 302, Flammability of Interior Materials, is a long, complicated, and detailed standard, as anyone who 
has read it knows. Its history, benefits, deficiencies, and primary effects on $C R$ design have been addressed elsewhere 2 and will not be repeated here. We do wish to highlight two aspects of this performance standard that seem to have a negative effect for consumers. The first is the buckle-release force, and the second is the size and shape of the three-year-old dummy.

The new buckles are too stiff. They are too diffleult for adults and way beyond the capabilities of young children. Because of manufacturing varlations, many buckles require more than 14 pounds of pressure to release, and we have measured them as high as 21 pounds. Parents in this study seemed to be generally satisfled with buckles only when the release-force was down around 12 pounds or less. Given this force level, the apparent ease of releasing a buckle also depended somewhat on its size and orientation in the hand. Although now buckle designs all have a single release button, it is possible that other mechanisms, such as two buttons squeezed together, would be more acceptable to parents and even more difficult for chlidren. It is also possible to make a buckle inaccessible to the chlld but easy to reach by an adult. Further research is needed into optimum forces, conflgurations, and locations of buckles, and FMVSS 213 should llow greater performance flexibility for the benefit of consumers.

Dynamic performance tests of TCRs use a standard "three-year-old" dummy. This dummy is 38.4 inches tall, weighs 33.2 pounds, and is dressed in a light shirt and short pants. The dummy is thus equivalent to a 68th percentile 36-month-old child (according to standard growth charts) in summer clothing. Although admittedly a subjective judgment, the dummy also seems to be proportioned on the slender side, especially in the shoulder and abdominal areas. The effect of having this single standard dummy is that the entire CR becomes tuned to it rather than to real children.

First, the restraining system must be optimlzed for use by the dummy. This becomes more of a problem with the less flexible systems, l.o., shields as opposed to harnesses. If a shield, for instance, is higher relative to a small child than it is to the dummy, not only is the child unhappy but it is possible the child wlll not be well restrained. Perhaps the six-month-old dummy, representing children at the low end of TCR use, should be incorporated by manufacturers into some forward-facing test programs. If a CR proves to be unacceptable for younger, smaller children but especially suited to older, larger children, the manufacturer should take advantage of the situation and market the CR accordingly. Potential consumer disappointment and disillusionment might thus be avoided.

Second, for lack of any other standard test device, the dummy has also been used to determine whether CRs can accommodate the size children they claim to be able to restrain.2s in the past, manufacturers have also often used this dummy as the upper size limit for determining harness length and perhaps even shell size. More recently, as designers have become more sensitive to these problems, extra webbing has been provided. But shell size remains fixed, and shields must still restrain a skinny dummy. All parties noed to 
recognize that winter clothing adds considerable girth to children. Our own brief investigation has found that a snowsult can add six inches to the length required for the lap straps alone. Guidelines are needed to ensure that CRs can in fact accommodate children they are intended to protect, so that use can be maintained as long as possible. If, however, an existing $C R$ design cannot be made to accommodate larger children but fits infants better than other CRs, the manufacturer should again recognize the situation and market it for a more limited but more realistic size range.

\subsection{Consumer Information Gaps}

The average consumer has very little understanding, if any, of what a child restraint system has to do and how it does its job. Even the few who have picked up pamphlets on the topic or read magazine articles get necessarily brief, incomplete, and sometimes inaccurate information. Even CR instructions fall under this description. Too often the do's and don'ts are not backed up with sufficient explanation. It is important for consumers to understand why they are doing certain things, not only to motivate them to do these things, but also to help them make intelligent decisions regarding compromises when the ideal is not possible. A good example would be whether it is better to use a CR in the front seat with tether anchored or in the back seat where no anchor is available. Although a difficult task, which might require some additional research into trade-offs among different restraining configurations, it should nevertheless be done to remove some of the "mystery" and misconceptions that now surround child restraints.

Parents need some guidelines as to what CR features are likely to be acceptable over time, both to them and to their children. Growth room, arm freedom, and overall simplicity should be emphasized. Parents of infants also need to be advised of the problems they may face with toddlers who try to assert their independence. All parents need to be aware of the full range of CRs availabie, not just the few that their local store may carry, so that families with special needs can find the best CR for them. Salespeople also need to be much more knowledgeable about their products, so that they can provide some real assistance and not just perpetuate old myths.

Finally, parents selecting a CR, particularly for a toddler, need an opportunity to try different models first hand. Even after using four or five, the parents in this study were unable to confidently evaluate somewhat unusual and unfamiliar designs. One parent was so pleased to be able to try the CRs, she would gladly have used all eight. Another said the experience would have been reward enough for being in the study, regardless of getting $a$ CR at the end. Local service organizations might offer trial packages for a small fee, or an enterprising retailer might offer a "satisfaction guaranteed" program as an inducement to buy. Manufacturers could also become involved and would benefit from the consumer feedback. Someone might even be able to organize a profitable CR leasing plan that would allow a client to exchange CRs as the child grew and the family's needs changed. Once mandatory child restraint use becomes nationwide, there may be considerable demand for these services. 


\subsection{Sources of Mlsuse and Non-Use}

Even among the relatively well-educated and motivated parents in this study, occasional misuse and non-use of the CRs occurred. MIsuse was reported in 12\% of the three-week use perlods and involved $40 \%$ of the familles. Non-use was reported in $33 \%$ of these periods and involved $56 \%$ of the families. Fortunately, most of these familles put their children in seatbelts, but some did not. Ten families said they always used the CRs as instructed.

The most frequently mentioned reason for not fastening the restraining system or, more likely, not using the CR at all was that the trip was "short." No $C R$ was immune from this behavior. Although it was difficult to separate the "hassle" factor from a perception of little or no risk, it was probably more the former for those who did not use a CR but still put their child in a seatbelt. For parents who do not restrain their children in these circumstances, information about crash and ejection risks, along with assurances that belts are not dangerous for chlldren, might persuade them to make the extra effort to at least put a seatbelt on their child.

Families were occasionally in situations where no CR was available, and seatbelts were usually used. When chlldren were sick, asleep, or fussy, or when there was no room in the car, seatbelts were not used. When tether anchors were not available, some used the $C R$ anyway, but others used seatbelts instead. Parents could use some guidelines as to which is the preferable arrangement.

Installation errors could be traced to insufficient information. Typically the belt was placed through the very bottom of the frame. A general knowledge that belts are routed high to keep CRs from pivoting forward might have helped. A more direct approach in this case, however, would have been labels on the frame itself to indicate the belt path. Installation diagrams, even when available, were apparently not always seen.

Failure to fasten or completely fasten the restraining system was
the most frequent form of misuse reported. Reasons for these occurrences were the hassle, child discomfort, and an incomplete understanding of how the restraining system worked. It is important to note for the purposes of this study that two CR restraining systems, both of whlch were consldered very easy and comfortable by the famllies who used thom, were always fastened when the CR was used. 


\subsection{CONCLUSIONS AND RECOMMENDATIONS}

Thirty-two families were involved in a long-term learning process that allowed them to select a child restraint that met the varied needs of both the child and the parents. Many of these parents had become disillusioned with CRs, because their own had not performed according to their expectations. The learning process included both individualized education from knowledgeable project staff and comparative experiences in each family's environment. The other new variable was the range of CR designs made available to the families.

Although strictly speaking the findings of this study can only be applied to this limited group of people, several conclusions can be drawn that need to be considered by CR designers, marketers, educators, and regulators. These conclusions and associated recommendations follow. All have a bearing on the major goal to reduce or eliminate misuse and non-use of child restraint systems.

Consumers. Consumers today are not likely to select the CR model that will best serve their family's needs by merely shopping for one in a store. Not only are their criteria likely to be inappropriate, but their perception of what meets some of these criteria may be distorted. Given education and hands-on experience with their child, however, both of these factors can change, and an optimal selection can be made.

Safety. Consumers have many misconceptions about how and why CRs work. These misconceptions can adversely influence their purchasing decisions and subsequent use habits. Parents need better information about CRs that emphasizes the functional aspects of the restraining system. Manufacturers and retailers should provide more such information in instructions and at the point of sale. Educators should recognize that parents need to know why they should do certain things, not merely that these things should be done. The development of educational materials emphasizing restraint theory, priorities, and trade-offs might also prove useful to professionals in the field.

Comfort. Child comfort and willingness to remain restrained in a $C R$ are probably the most critical factors influencing parental satisfaction and thus the likelihood the CR will be used. Parents, however, are often unable to anticipate whether their child will be comfortable in a given CR. In addition, CRs are not always designed with the child's needs in mind, the most important being freedom of arm movement, good visual field, and a restraining system that is flexible enough to accommodate different size bodies in various clothing. Many CRs do not suitably accommodate the size-range of children for whom they claim to be designed.

Educators should advise parents as to what design configurations are likely to be acceptable to children of different shapes and sizes. Regulators need to recognize that the standard test dummy may be influencing design in an inappropriate manner. Manufacturers should reevaluate their products and provide new designs, modifications to old ones, or estimates of their market audience. Retailers and other CR distributors should facilitate trial periods and encourage the return of 
unacceptable CRs. Perhaps it is unrealistic to think that a CR can be designed that is really suitable from birth through age 4 . If so, educators need to advise parents that two or even three CRs may be necessary, with the additional benefit that older children may then be more likely to be restrained. To minimize economic hardship, innovative trade-in and distribution schemes will need to be developed.

Convenience. CRs vary considerably in the number of operations that must be performed in order to restrain a child. These operations include not only fastening the restraining system, but also preparing the system so the child can get in and obtaining access to the system for fastening. The fower the operations, the more acceptable the system is to parents. There is also some indication that the less there is to do, and thus the less time involved, the more likely it is that the aystem will be fastened. Educators should provide parents with Information about the full range of restraining system configurations so that parents can be aware of all the options. Retallers and other distributors should provide the widest selection possible. Manufacturers should continue to develop deslgns that $m|n| m \mid z e$ parental effort while still being comfortable for. a child.

POSTSCRIPT: Even as this report was being written, one of the families in the study was involved in an accident. It was not severe, but the frontal impact resulted in knee injuries to the unrestrained driver. The child, however, was properly restrained in his new CR in the center of the back seat and received not a scratch. The rewarding aspect of this incident is that, prior to their participation in the study, the child regularly escaped from his CR harness and was therefore usually unrestrained. If this accident had happened then, the child would probably have been injured. 


\subsection{REFERENCES}

1. Kielhorn, T.G., and Westphal, J. A study of the use and non-use of child restraint devices in metropolitan Oklahoma. Oklahoma City: Oklahoma Survey Consultants, 1980. 207p.

2. Hall, W.L., and Council, F.M. "Effects of pediatric education on the use of child restraint devices in North Carolina." Proceedings of the 23rd Conference of the American Association for Automotive Medicine. Morton Grove, 111.: AAAM, 1979, Pp. 104-115.

3. Philpot, J.W., Heathington, K.W., Perry, R.L., and Hughes, E.C. The use of child passenger safety devices in Tennessee. Knoxville: The University of Tennessee, Transportation Center, 1978. 29p.

4. Phillips, B.M. 1. Safety belt usage among drivers. 11 . Use of child restraint devices, passenger safety belts and position of passengers in cars. 111 . Motorcycle helmet usage. Final report. Princeton: Opinion Research Corporation, 1980. 86p. (Report no. DOT HS-805-398.)

5. Weber, K. "Survey of infant restraint usability." Proceedings of the 24th Conference of the American Association for Automotive Medicine. Morton Grove, 111.: AAAM, 1980, PP. 88-102.

6. Philpot, J.W., et al. Tennessee Child Passenger Safety Program, 1978 annual report. Knoxville: The University of Tennessee, Transportation Center, 1979. 135 p. (Report no. DOT HS-805-017.)

7. Hoadley, M.R., Macrina, D.M., and Peterson, F.L. "Child safety programs: Implications affecting use of child restraints." The Journal of School Health, vol. 5, May 1981, pp. 352-355.

8. Christophersen, E.R. "Children's behavior during automobile rides: Do car seats make a difference?" Pediatrics, vol. 60, July 1977, pp. 69-74.

9. Cunningham, J.L., Hughes, E.C., Philpot,. J.W., and Pentz, C.A. Parents' knowledge, attitudes and behavior about child passenger safety. Knoxville: The University of Tennessee, Transportation Center, 1981. 76p. (Report no. DOT HS-805-947.)

10. Hall, W.L. "Warning: In cars children may be hazardous to their parent's health: The role of restraints in preventing collisions." Proceedings of the 24th Conference of the American Association for Automotive Medicine. Morton Grove, 111.: AAAM, 1980, pp. 132-146.

11. Netterfield, S. Childproofing child restraint systems. Rosebery: New South Wales Department of Motor Transport, Traffic Accident Research Unit, 1981. (Unpublished draft.) 
12. Freedman, R., and Lukin, J. Oceupant protection for chllaren: $A$ survey of restraint usage, attltudes and knowledge. Rosebery: New South Wales Department of Motor Transport. Traffic Accldent Research Unit, 1977. 228 p.

13. Weber, K. Infant restraint usabllity follow-up. Ann Arbor: The University of Michigan, Highway Safety Research Institute, 1981. 4p.

14. Arnberg, P.W. Child restraint systems: Handling performance of buckles and harnesses on child seats. Linkoping: National Swedish Road and Traffic Research Institute, 1974. 59p.

15. Arnberg, P.W. Child restraint systems: Handling performance of buckles on child seats with regard to opening force requirements. Linkoping: National Swedish Road and Traffic Research Institute, 1975. 20p.

16. Meivin, J.W. "Developments in infant and child occupant restraint systems in the United.States." International Symposium on Occupant Restraint Proceedings. Morton Grove, 111.: American Association for Automotive Medicine, 1981; pp. 183-188.

17. Arnberg, P.W., Arnberg, L., and Trinca, G.W. "Practical aspects of chlld restraint system use." Restraining the Child in a Car Seminar. Melbourne: Royal Australian College of surgeons, 1978. $32 p$.

18. Trinca, G.W., Arnberg, P.W., and Arnberg, L. "Evaluation of different types of child restraint systems for cars." Accident Analysis and Prevention, vol. 13, 1981, pp. 11-16.

19. Tom, J.C., Petersen, D.D., Robbins, C.M., and Peters, R. Evaluation of the comfort and convenience of safety belt systems in 1980 and 1981 model vehicles. Rockvilie, Md.: Verve Research Corporation, 1981, pp. 87-90. (Report no. DOT HS-805-860.)

20. Pless, I.B., and Roghmann, K.J. "Safety restraints for children in automobiles." Canadian Journal of Public Health, vol. 69, July/ August 1978, pp. $289-292$.

21. Laboratory procedure for testing child restraint systems: Federal Motor Vehicle Safety Standard No. 213. Washington, D.C.: National Highway Traffic Safety Administration, 1981. Report no. $T p-2(3-02$. 
APPEND IX

53 
I.D. \#-

$C R$

EVALUATION OF INSTRUCTIONS

1. Overall, how eastly could you follow these instructions?

2. Were there any words, phrases, or diagrams that you found confusing (or that you think someone else following these instructions might find confusing)?

3. Were the instructions comprehensive? Were there things that you wanted to know that they did not cover?

4. Were there any things about these instructions that you especially liked or found helpful?

5. Any other comments? 


\section{I.D. \#}

POST-TRIAL INTERVIEW

CR

1. General Reaction

a. Generally, how did you like the CR?

b. How did your child like it?

\section{Instructions}

a. Did you read the instructions at some time? Yes Partly No

b. Could you comment about how clear, helpful, well-written, etc. they were?

\section{Installation}

a. Did you reinstall the $C R$ in another seat or in a different car?

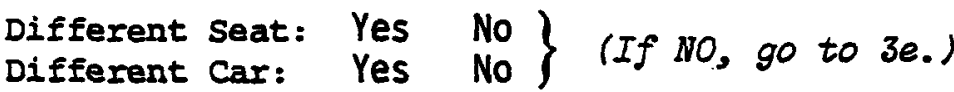

b. Did you have any problems?

(What did you do with the tether?) 
3. c. Did you need to refer to the labels or instructions? Yes No Were they helpful?

d. Did you ever use the $C R$ without attaching the vehicle Yes No belt?

Under what circumstances?

Without attaching the tether?

Yes No

Under what circumstances?

e. Which seat position was the CR usually used In?

f. Can you suggeat any design changes that would make the CR easier to install?

g. Did you have any trouble getting your child to sit in the CR? 
4. Harness/Shield/Buckle

a. Did you have any trouble with the harness and/or shield/arm rest, either adjusting it or fastening/securing it?

b. Did you need to refer to the labels or instructions? Yes No Were they helpful?

c. Did your child object to or resist putting on the harness/shield?

d. Was your child able to get out of the hamess/shield Yes No himself (herself)?

Was this a problem?

e. Did you ever let your child ride without the harness/ Yes No shield fastened/in place?

Under what circumstances? 
4. f. Can you suggest any design changes that would make the harness/ shield easier to use?

\section{Child Comfort}

a. Once in place, do you think your child was comfortable while riding in the CR?

b. Did he/she have any specific complaints?

c. Did you do anything to increase your child's comfort?

d. Can you suggest any design changes that would make the $\mathrm{CR}$ more comfortable? 
6. Positive Features

Was there anything you particularly liked about the CR? AnY advantages over others you have seen or used?

What about the upholstery?

7. Usage

a. Were there any times you did not use the $C R$ at all? Yes No What were the circumstances?

b. How did your child travel?

8. Cost

a. If cost were not a factor, would you be happy with Yes No this CR?

b. (If YES:) This CR retails for about $\$$ would you be willing to pay that price for it?

Yes No

9. Demonstration 